\title{
El fenómeno de la dispersión residencial en la Región Metropolitana de Barcelona. Espacios, actores y tendencias*
}

\author{
Arlinda García Coll \\ Universitat de Barcelona. Departamento de Geografía \\ arlindagarcia@ub.edu \\ Cristina López Villanueva \\ Universitat de Barcelona. Departamento de Sociología \\ clopez@ub.edu
}

\section{Resumen}

Este artículo aborda la dispersión residencial (sprawl) en la Región Metropolitana de Barcelona (RMB) durante el período 1996-2015, con el objetivo dar cuenta del impacto sociodemográfico causado por este fenómeno. El trabajo parte del estudio de la movilidad residencial con destino a los municipios de baja densidad de la RMB, teniendo en cuenta sus repercusiones en el mercado de la vivienda, en la estructura demográfica y en la composición social.

Los municipios con amplia representación de urbanismo disperso de la RMB se identifican a partir de una baja densidad neta y de un alto porcentaje de viviendas aisladas. Su análisis se basa en el cálculo de las tasas de movilidad residencial por edad, las tasas de nueva construcción y, según la tipología edificatoria, el crecimiento de la población, el cálculo de indicadores de estructura y de la renta familiar per cápita. Se cuenta, además, con información adicional procedente una encuesta propia titulada Movilidad, solidaridad familiar y ciudadanía en la Región Metropolitana de Barcelona, realizada en 2005.

Los resultados muestran el gran atractivo residencial de los municipios dispersos que se debilita con el inicio de la crisis económica. La incidencia de inmigración retroalimenta unas tasas de construcción igualmente intensas que provocan un crecimiento sin precedentes de la población, lo que modifica profundamente su disposición - la rejuvenece a partir de la llegada de parejas jóvenes con hijos menores-, a la vez que transforma la estructura social como consecuencia de la atracción de un elevado porcentaje de familias de rentas medias y altas.

* Este artículo forma parte del proyecto I+D+i titulado Transformación urbana en un contexto de crisis en las periferias urbanas de las grandes áreas metropolitanas de España: El caso de la $R M B$. Ref. CSO2013-48075-C2-1-R. 
En las conclusiones, se reflexiona sobre los retos que deben afrontar estos municipios sometidos a un rápido cambio sociodemográfico, así como sobre el futuro de la movilidad con destino a unas áreas dispersas.

Palabras clave: movilidad residencial; urbanismo disperso; estrategias residenciales; suburbanización; cambio estructural.

Abstract. Residential Sprawl in the Barcelona Metropolitan Region: Areas, Actors and Trends

This article focuses on residential sprawl in the Metropolitan Region of Barcelona (RMB) during the period 1996-2015 in order to account for the demographic impact caused by this phenomenon. This research takes as its starting point the analysis of residential mobility to low-density municipalities, considering its impact on the housing market, demographic structure and social composition. Municipalities with marked urban spread are identified according to lower net density and a higher percentage of isolated houses. The analysis is based on the calculation of residential mobility rates by age, rates of new construction according to building type, population growth, indicators of family structure and per capita income. Additional information from the Mobility Family Solidarity and Citizenship Survey in the Metropolitan Region of Barcelona, 2005 is also used. The results reveal the large residential attractiveness of disperse municipalities that weaken with the onset of the economic crisis. The incidence of immigration gives rise to equally intense construction rates that lead to unprecedented population growth, which profoundly modifies the population structure-rejuvenated by the arrival of young couples with small children-and transforms the social structure as a result of the arrival of a high percentage of middle- and high-income families. The conclusions reflect on the challenges faced by these municipalities undergoing rapid demographic change and on the future of the outgoing mobility to dispersed areas.

Keywords: residential mobility; urban sprawl; residential strategies; suburbanization; structural change

\section{Sumario}

$\begin{aligned} \text { 1. Introducción. La dispersión residencial } & \text { 2. Fuentes y métodos } \\ \text { como factor de transformación en las } & \text { 3. Resultados } \\ \text { periferias urbanas españolas. El caso de la } & \text { 4. Conclusiones } \\ \text { Región Metropolitana de Barcelona } & \text { Referencias bibliográficas }\end{aligned}$

\section{Introducción. La dispersión residencial como factor de transformación en las periferias urbanas españolas. El caso de la Región Metropolitana de Barcelona}

La dispersión residencial en España ha sido un factor que ha transformado la configuración territorial, demográfica y social de las periferias urbanas de nuestro país desde finales de la década de 1980 hasta la actualidad. Así lo señalan trabajos como los de Catalán et al. (2008), Muñoz (2010 y 2011), Nel.lo (2011), Feria y Albertos (2010) o Muñiz y García-López (2013). El principal 
pilar de esta transformación se encuentra en el incremento de la movilidad residencial con destino a zonas caracterizadas por su baja densidad y por el predominio de una tipología de vivienda unifamiliar. Existe, pues, una preferencia residencial por este tipo de áreas en aumento y un número creciente de familias que las eligen como lugar de residencia (Barba y Mercadé, 2006; Domínguez, 2014). Se trata de hogares que toman como opción residencial vivir en disperso, lo que significa, en la mayoría de ocasiones, instalarse en una urbanización más o menos alejada del centro urbano del municipio de destino. Esta modalidad migratoria forma parte destacada de los movimientos suburbanizadores que han tenido gran relevancia en nuestro país en las últimas tres décadas (Susino y Duque, 2013; García Coll, 2009; Recaño, 2015), pero que, por sus particularidades, despierta un interés especial. Si bien una de las características específicas del modelo de dispersión de las áreas metropolitanas mediterráneas es la presencia de baja densidad mixta (Catalán et al., 2008), es decir, con presencia de viviendas multifamiliares de baja altura, con espacios verdes compartidos y situadas en zonas periféricas — pero no desvinculadas de la trama urbana compacta—, sobre todo de subcentros de tamaño medio, el objeto de estudio de este trabajo se centra en las urbanizaciones precisamente por sus rasgos de lejanía del núcleo central de los municipios en las que se ubican. En estos casos, la decisión de trasladarse a una urbanización supone asumir un desplazamiento que lleva a habitar lo que cabría considerar como la periferia de la periferia. Esta decisión es la mejor demostración de una clara preferencia por una serie de valores residenciales frente a otros, de preferir un modo de vida en disperso al modelo de vida en compacto. Por otro lado, su impacto en cuanto a la ocupación del espacio, al crecimiento de la vivienda o a la transformación de su contenido sociodemográfico enlaza directamente con uno de los temas centrales en el urbanismo de nuestros días, como es el de la sostenibilidad, tanto en su dimensión medioambiental (Herce y Magrinyà, 2007) como también en la social (Henry, 2007; Vilà y Gavaldà, 2013). En definitiva, el resultado es una nueva periferia cuya realidad ya forma parte de la nueva configuración socioespacial de los alrededores metropolitanos. Su gestión y la acción sobre esos espacios y sus residentes es un elemento a incluir en las agendas de futuro de investigadores, políticos y otros actores sociales (Nel.lo, 2011; Hortas-Rico y Solé-Ollé, 2010; Mur y Clusa, 2011; Gielen, 2016). Por este motivo, su conocimiento y caracterización son del todo necesarios, así como la reflexión sobre su futuro, sin, por supuesto, olvidar su pasado.

Este artículo se centra en el análisis del fenómeno de la dispersión residencial en las áreas urbanas españolas a partir del estudio del caso de la Región Metropolitana de Barcelona (RMB). Su objetivo es mostrar el impacto causado por este fenómeno a nivel sociodemográfico, con el fin de identificar los factores clave del sprawl residencial en una región urbana madura y consolidada como la de Barcelona, además de delimitar su capacidad transformadora y sus consecuencias. Sin duda, el elemento desencadenante de este proceso es la creciente movilidad residencial hacia estas áreas, pero, sin embargo, el análisis 
no puede ceñirse exclusivamente a la perspectiva migratoria, sino que tiene que dar cabida a otros aspectos relacionados con el mismo, tales como el mercado de la vivienda, su estructura demográfica o su composición social. Además, pese a que el énfasis está puesto en las áreas receptoras, es decir, en los municipios caracterizados por su baja densidad, tampoco puede perderse de vista lo que sucede en los principales lugares de partida, como son aquellos que presentan rasgos acentuados de compacidad. En un espacio relativamente reducido y, sobre todo, fuertemente interconectado como es la RMB (Miralles y Tulla, 2012), lo que sucede en una determinada categoría municipal afecta a las restantes y viceversa. Por tanto, podemos afirmar que estamos frente a un proceso de reajuste de las dinámicas urbanas metropolitanas en toda su dimensión.

Este artículo se estructura en cuatro partes. En la primera, se lleva a cabo una propuesta de definición y metodología para el estudio del urbanismo disperso en la RMB. En la segunda, se caracteriza la movilidad residencial con destino a estos municipios, factor que genera las transformaciones que se analizan a continuación: en el mercado de la vivienda (punto 4.1), en el volumen y en la estructura de su población (puntos 4.2 y 4.3), y, finalmente, en el componente social de las áreas objeto de estudio (punto 4.4). Para terminar, las conclusiones traerán a la luz un balance sobre la conexión entre la movilidad residencial y los fenómenos de cambio social y urbano en la realidad metropolitana de ciudades como Barcelona.

\section{Fuentes y métodos}

\subsection{Cómo definir y estudiar el urbanismo disperso. Apuntes metodológicos a partir del caso de la $R M B$}

Uno de los primeros retos a abordar para avanzar en la investigación que se presenta ha sido la propia definición y el hecho de operativizar el urbanismo disperso. A pesar de ser un tema que ha suscitado gran interés, tanto a nivel teórico como aplicado, su estudio cuenta con ciertas limitaciones que han requerido plantear estrategias metodológicas previas.

En primer lugar, no se dispone de una definición consensuada de urbanismo disperso, circunstancia que dificulta el establecimiento de criterios para su delimitación territorial. En segundo lugar, existe una grave limitación en las fuentes de información disponibles, lo que obliga a realizar una aproximación indirecta a partir del conjunto municipal, así como a buscar fuentes complementarias a las bases de datos ordinarias, caso de los datos obtenidos a través de encuestas.

\subsection{La compleja definición y medición del urbanismo disperso}

En términos generales, se entiende por urbanismo disperso la modalidad de crecimiento metropolitano que realiza una ocupación extensiva del suelo. Esta práctica da lugar a densidades de población muy bajas, indicador que, 
de hecho, se convierte en el más utilizado para su identificación. En otros casos, y cuando es posible, esta perspectiva se afina considerando la presencia de elementos urbanos aislados morfológicamente y funcionalmente, donde la tipología dominante incluye viviendas unifamiliares aisladas (López de Lucio, 1998 y 2004; Muñoz, 2011). En el caso de España, este fenómeno corresponde mayoritariamente a la presencia de urbanizaciones, las cuales se caracterizan por su discontinuidad de la trama municipal consolidada (Nel·lo, 2011). López de Lucio (1998) completaba la definición añadiendo como elementos definitorios una segregación social acentuada, una disminución de las relaciones sociales de proximidad y, finalmente, un empobrecimiento, una especialización y una privatización de los espacios. Otras aportaciones insisten en este tipo de rasgos y añaden algunos más, como una identidad frágil, una gran dependencia del transporte privado, una escasez de espacio público y un derroche en la gestión de recursos naturales (CECS, 2005; EAA, 2006). En definitiva, apuntan a los ámbitos dispersos como espacios específicos de rico debate sobre los procesos sociales que protagonizan, además de los de índole medioambiental. Sin embargo, la demostración empírica de estos procesos asociados al urbanismo disperso en España entraña una enorme dificultad, debido a la falta de información específica para estas áreas. Dicha circunstancia obedece, por un lado, a la falta de correspondencia de la delimitación por sección censal a otras realidades territoriales como las urbanizaciones, de manera que no es posible reconocerlas o reconstruirlas a partir de los datos censales o padronales.

Para solventar estas limitaciones, se ha desarrollado una estrategia metodológica que permite realizar una aproximación al fenómeno del urbanismo disperso a partir de considerar la superficie de suelo urbano de uso residencial (variable que posibilita el cálculo de la tasa de densidad neta) y la superficie del municipio dedicada a "ordenaciones extensivas de baja densidad, de casa unifamiliares o bifamiliares adosadas (apareadas) aisladas en una parcela con jardín». Esta información está disponible para el conjunto de municipios de Catalunya a través del Mapa Urbanistic de Catalunya (MUC) realizado por la Direcció General d'Ordenació del Territori i Urbanisme de la Generalitat de Catalunya.

La utilización de la densidad es uno de los criterios más comunes en la medición del fenómeno de la dispersión residencial (Ewing et al., 2002). Diversos trabajos recientes utilizan la densidad neta para estudiar el urbanismo disperso, en ocasiones combinado con la distancia y/o la discontinuidad con el centro a partir de la observación a través de Corine Land Cover (CLC) (Díaz-Pacheco y García-Palomares, 2014). El uso de la densidad neta permite relacionar la población municipal con la superficie de suelo urbano destinado a uso residencial y no con la extensión total, recurso que permite una mejor aproximación a la dispersión residencial. Por otro lado, el porcentaje de suelo destinado a casas aisladas facilita la identificación de los municipios donde la presencia de urbanizaciones tiene mayor peso, dado que la vivienda unifamiliar es la modalidad residencial predominante en las mismas. Cabe recalcar que, frente a la utilidad demostrada en otros casos 
Tabla 1. Clasificación de los municipios de la RMB según el uso del suelo

\begin{tabular}{lcccccc}
\hline Tipo & $\begin{array}{c}\text { Número de } \\
\text { municipios }\end{array}$ & $\begin{array}{c}\% \\
\text { municipios }\end{array}$ & $\begin{array}{c}\text { Población } \\
(\mathbf{1 / 1 / 2 0 1 5 )}\end{array}$ & $\begin{array}{c}\% \\
\text { población }\end{array}$ & $\begin{array}{c}\text { Densidad } \\
\text { neta hab/ha }\end{array}$ & $\begin{array}{c}\% \text { suelo casas } \\
\text { aisladas }\end{array}$ \\
\hline Compacto & 22 & 13,4 & 3.243 .614 & 64,5 & 576,7 & 10,2 \\
Intermedio & 36 & 22,0 & 1.070 .608 & 21,3 & 223,4 & 42,4 \\
Disperso & 106 & 64,6 & 714.036 & 14,2 & 50,5 & 82,3 \\
Total & 164 & 100,0 & 5.028 .258 & 100,0 & 204,8 & 58,0 \\
\hline
\end{tabular}

Fuente: elaboración propia a partir del Mapa Urbanístic de Catalunya. Direcció General d’Ordenació del Territori i Urbanisme de la Generalitat de Catalunya (2015) e INE, Padrón Continuo 2015.

del enfoque cartográfico en el análisis de la dispersión a partir de fotografías aéreas o imágenes satélite (Catalán et al., 2008; Ewing et al., 2002) y su posterior tratamiento con SIG, nuestro análisis pretende respetar la división administrativa municipal, con el fin de poder utilizar los datos demográficos, tanto de crecimiento de la población como de dinámica natural o migratoria. Estas fuentes son las únicas que permiten realizar una contextualización de las dinámicas demográficas actuales y sus cambios recientes con el fenómeno de la dispersión.

De la combinación de estos dos indicadores, resulta una clasificación que permite agrupar a los municipios de la RMB según su grado de dispersión y compacidad a partir de la intensidad de las variables seleccionadas (tabla 1 y figura 1).

La clasificación obtenida es la siguiente:

a) Compacto o alta densidad. Incluye los municipios con una densidad neta superior a $350 \mathrm{hab}$./ha y un porcentaje muy bajo de suelo destinado a casas unifamiliares. Esta categoría representa un número reducido de municipios (el 13,4\%), pero, en cambio, alberga a más del $60 \%$ de la población.

b) Intermedio. Incluye los municipios con una densidad entre 140 y 350 hab./ha. Esta categoría alberga una proporción ligeramente superior al 20\%, tanto en la proporción de población como de número de municipios, con una densidad media de $223 \mathrm{hab}$./ha y un porcentaje del suelo destinado a casas aisladas del $42 \%$.

c) Disperso o baja densidad. Incluye los municipios con una densidad inferior a 140 hab./ha y con más del $80 \%$ de la superficie destinada a casas aisladas. Este tipo representa un porcentaje bajo de población (un 14\%) y alcanza casi un 65\% de los municipios de la RMB.

El análisis del urbanismo disperso en este trabajo se lleva a cabo a partir de la observación de los datos que se refieren a los municipios caracterizados por su baja densidad resultante de la agrupación anterior, que responden a la denominación de dispersos. En algunos momentos, es de utilidad contrastar la trayectoria seguida por estos con la experimentada por los municipios más densos, que responden a la designación de compactos. 
Figura 1. Clasificación de los municipios de la RMB según el uso del suelo

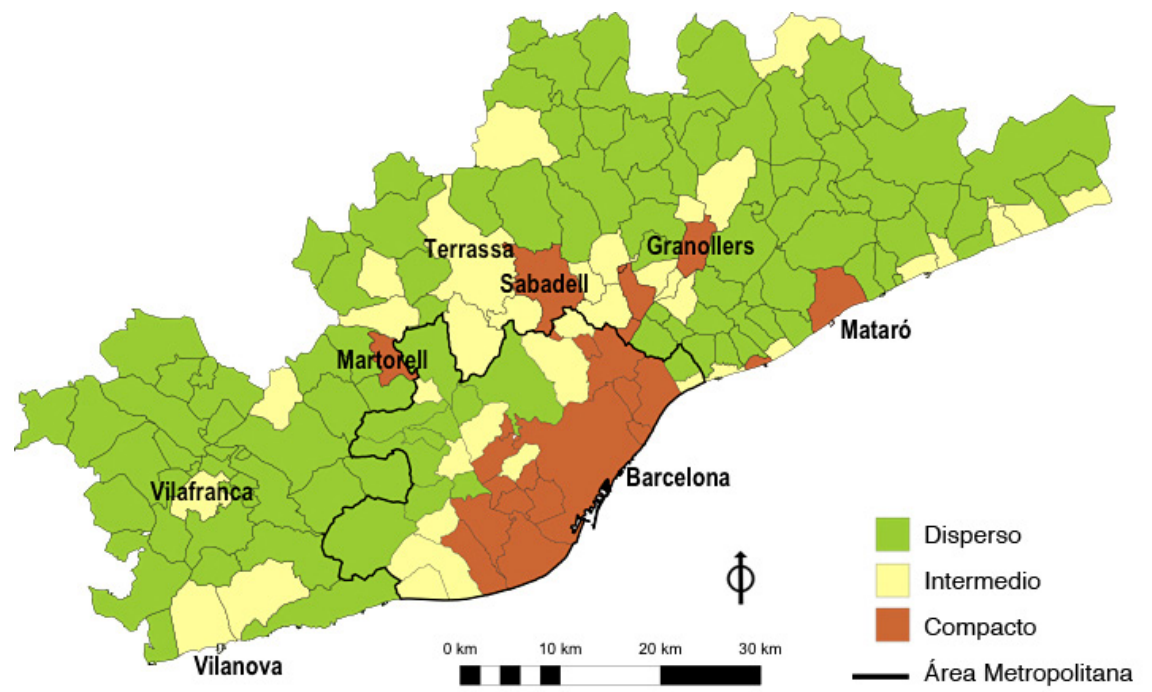

Fuente: elaboración propia a partir de los datos del Mapa Urbanístic de Catalunya. Direcció General d'Ordenació del Territori i Urbanisme de la Generalitat de Catalunya (2015) e INE, Padrón Continuo 2015.

\subsection{Fuentes para estudiar la movilidad residencial y su impacto sociodemográfico en España}

Una vez resuelta la acotación territorial del urbanismo disperso, se ha procedido a la búsqueda de datos que permitan su caracterización y el análisis de los cambios experimentados en el tiempo. Esta caracterización se ha llevado a cabo en base a tres grandes apartados. En primer lugar, debido a su transcendental papel en la transformación de dichas áreas, se ha procedido a analizar la evolución de la nueva construcción a partir de los expedientes de viviendas iniciadas (obra nueva) según su tipología edificatoria. Estos datos proceden de los visados de obra de los colegios de aparejadores, arquitectos técnicos e ingenieros de edificación de Cataluña y presentan la ventaja de que permiten, también, focalizar la atención en la construcción de viviendas unifamiliares a escala municipal. La serie utilizada abarca el período 1999-2014.

En segundo lugar, los cambios demográficos son analizados a partir de la Estadística de Padrón Continuo para el período 1998-2015, al que se suman, cuando son necesarios, los datos del Censo de Población de 1991 y del Padrón Municipal de Habitantes 1996. Para completar este apartado, se realiza un análisis específico del papel de la movilidad residencial a partir de los microdatos de la Estadística de Variaciones Residenciales (EVR) correspondiente al período 2002-2014. 
La aproximación a la realidad social de dichos ámbitos se ve obstaculizada por las escasas fuentes que proporcionan datos para el conjunto de municipios españoles, de manera que, a posteriori, estos puedan ser agregados de acuerdo con la tipología empleada en este estudio. Cabe recordar que la última operación padronal, correspondiente al Censo de Población de 2011, no fue universal, circunstancia que imposibilita generar datos municipalizados que permitan realizar una aproximación afinada a la estructura social. En este artículo, se recurre a los datos de la renta bruta familiar disponible procedentes del Servicio de Información Económica Municipal (SIEM) de la Diputación de Barcelona. Esta fuente brinda series temporales suficientemente amplias como para apreciar los comportamientos precrisis y poscrisis, además de ofrecer datos con desagregación municipal.

La caracterización sociodemográfica de los residentes en áreas dispersas se completa por medio de los resultados de la encuesta titulada Movilidad, solidaridad familiar y ciudadanía en la Región Metropolitana de Barcelona (2005)․․ Esta encuesta se realizó en el año 2005, en el marco del proyecto del mismo título, y recogió información de 600 hogares (1.924 individuos) de personas que se habían trasladado a vivir a una urbanización de la RMB. Gracias a su diseño muestral, es representativa de la población residente en urbanizaciones de la RMB, con una muestra de 17 municipios y 24 urbanizaciones. Los municipios se seleccionaron a partir de una clasificación resultante de análisis multivariante según la migración neta intrametropolitana entre 1992-2000, la densidad neta, la tasa de nueva construcción y la proporción de viviendas unifamiliares. En definitiva, se obtiene información sobre características familiares, laborales, económicas y demográficas de los entrevistados. Entre una amplia batería de preguntas, se incluyen algunas de gran utilidad para el estudio de la movilidad residencial, como, por ejemplo, los motivos por los que se eligió una urbanización como lugar de residencia. Aunque esta encuesta fue realizada en 2005, sus resultados son de gran utilidad para explicar el proceso de configuración del fenómeno de la dispersión residencial. Además, permite conocer de primera mano algunos detalles sobre la toma de decisión de la migración o las características socioeconómicas y familiares de los nuevos pobladores de dichas áreas. Este tipo de información no es aportada por ninguna otra fuente disponible $y$, en cambio, resulta fundamental para contextualizar las tendencias que se irán detectando. De ahí el valor otorgado al uso de la misma.

Por último, en el presente artículo, se emplea una perspectiva temporal lo suficientemente amplia como para poder mostrar las tendencias que explican la configuración actual de los espacios estudiados. A pesar de que el interés se centra en las transformaciones experimentadas en el período en conjunto, será inevitable hacer referencia al cambio de tendencia que sucede tras el inicio de

1. Encuesta realizada en el marco del proyecto coordinado $++D+i$ que lleva por título Movilidad, solidaridad familiar y ciudadanía en las Regiones Metropolitanas. Ref. SEC2003-09565$\mathrm{CO} 2$, cuyas investigadoras principales fueron Anna Alabart e Isabel Pujadas. 
la crisis, momento en el que se truncan las trayectorias de la mayoría de indicadores analizados, lo que dará pie a la llegada de una nueva etapa.

\section{Resultados}

\subsection{Movilidad residencial hacia municipios dispersos. ¿Por qué irse a vivir a una urbanización?}

El aumento de la movilidad residencial en España en el transcurso de las últimas tres décadas es, sin duda, la característica más destacada del panorama reciente de las migraciones internas en nuestro país y el principal factor explicativo de la redistribución reciente de la población (Recaño, 2015; Susino y Duque, 2013; García Coll, 2009). En una sociedad como la española, caracterizada tradicionalmente por una movilidad residencial de su población de baja intensidad, este cambio dibuja un escenario totalmente novedoso. La movilidad residencial actual se manifiesta, además, siguiendo un marcado patrón territorial: las ciudades — sea cual sea su tamaño — resultan ser lugares preferentes de salida de flujos que se dirigen hacia municipios más o menos próximos a las mismas, con lo que se convierten en su zona de expansión residencial. En el caso de las grandes urbes, esta expansión residencial alcanza municipios situados en coronas cada vez más alejadas de la población central (Rubiera et al., 2016; Díaz-Pacheco y García-Palomares, 2014; Pujadas, 2009; Moliní y Salgado, 2012). La relación entre precio y calidad (características o equipamientos) de la vivienda, el hecho de presentar una oferta residencial diferenciada a la de la ciudad (unifamiliar, con jardín, con piscina, etc.) o en un entorno de mayor calidad ambiental son razones que motivan este tipo de desplazamientos.

Un buen ejemplo de esas nuevas pautas migratorias se encuentra en la RMB. En dicha región, la movilidad intrametropolitana se dobla entre 1996 y 2006, año en el que se registra el número máximo de desplazamientos (159.811). Durante ese período, las tasas de migración pasan de un 15,7\%o a un 33\%, y son especialmente intensas durante el período de mayor bonanza económica, entre 2002 y 2006. La irrupción de la crisis no finiquita este patrón de elevada movilidad, aunque sí modera ligeramente su intensidad (figura 2). Los intercambios migratorios en la RMB se estabilizan a partir de 2008, en torno a 137.000 desplazamientos anuales y a tasas del $28 \%$. Aunque el incremento de la movilidad puede asociarse parcialmente a la creciente presencia de población extranjera — caracterizada por una mayor movilidad ampliamente documentada por trabajos como los de Recaño (2015), Bayona y Gil (2008) o Pumares et al. (2006) - también se observa que su papel se estanca a partir de 2008 (cuando representaban el 40\% de los desplazamientos), siendo en 2015 poco más de una cuarta parte (un 26,1\%). Por tanto, el papel de los extranjeros en las variaciones de los patrones migratorios más recientes es más bien moderado y no cabe atribuir a los mismos los cambios de comportamiento detectados. 
Figura 2. Evolución de la migración intrametropolitana en la RMB (1996-2015)

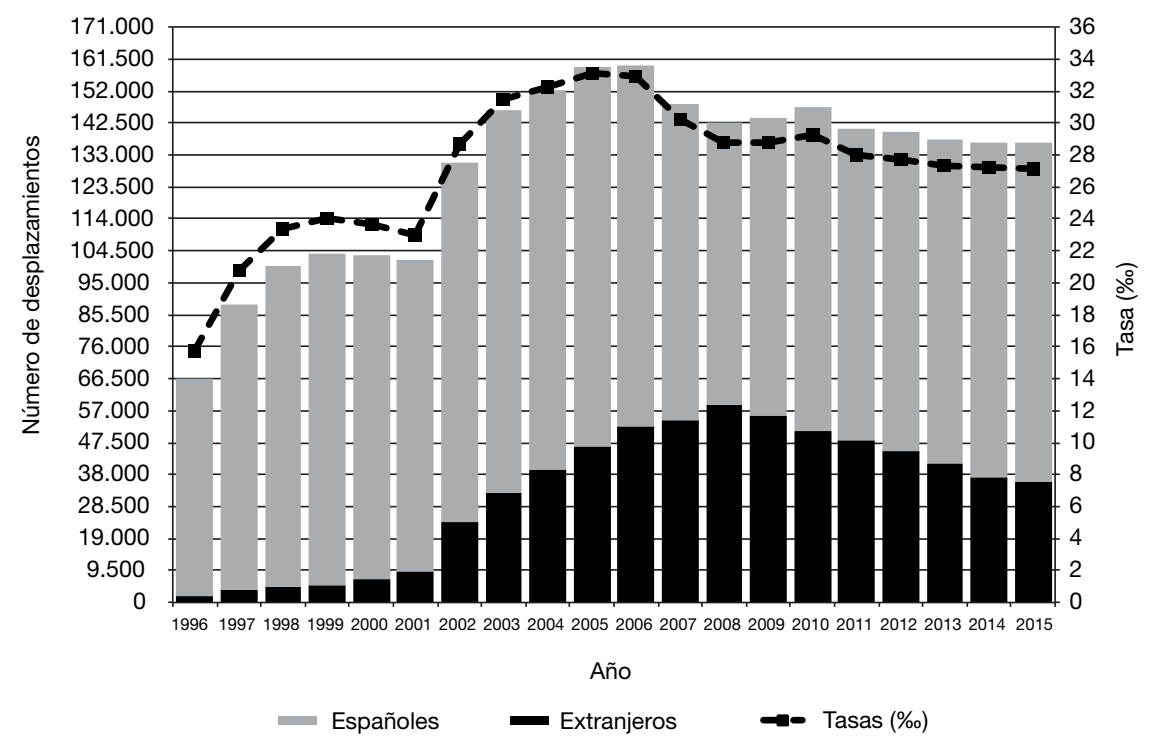

Fuente: elaboración propia a partir del INE: Estadística de Variaciones Residenciales 1996-2015. Fichero de microdatos. Padrón Municipal de Habitantes 1996 y Padrón Continuo 1998-2016.

El mejor reflejo del patrón territorial de las migraciones se obtiene cuando se compara la evolución de las tasas en el período 1996-2015, diferenciando entre municipios dispersos y municipios compactos (figura 3 ).

En el contexto metropolitano, los municipios dispersos actúan como áreas de fuerte atracción residencial, tal como reflejan las nutridas tasas de inmigración que registran, especialmente desde 1998 hasta 2006 (figura 3a). Durante dicho período, la inmigración presenta tasas superiores al $60 \%$, que duplican la media metropolitana. A partir de 2006, se aprecia un drástico descenso de la inmigración, de forma que las tasas disminuyen en 20 puntos en tan solo tres años, hasta que, a partir de 2011, se estabilizan en valores cercanos al $40 \%$. Como consecuencia de una fuerte entrada inmigratoria, los municipios dispersos presentan un crecimiento migratorio muy cuantioso, con tasas netas superiores al 25\% durante casi una década. El efecto de esta migración intensa y prolongada en el tiempo es suficientemente notable como para significar una inflexión en la trayectoria sociodemográfica de estas áreas. Si bien es cierto que el proceso de dispersión residencial se debilita en la etapa más reciente, cuando las tasas descienden y vuelven a niveles registrados en 1996, la huella de lo sucedido hasta el momento es de tal calado que ha transformado profundamente la realidad de estos municipios. Por tanto, a pesar de la desaceleración del fenómeno en los últimos años, su incidencia en las circunscripciones afectadas 
Figura 3. Evolución de las tasas migratorias intrametropolitanas en el periodo 1996-2015 (\%o) a) municipios dispersos

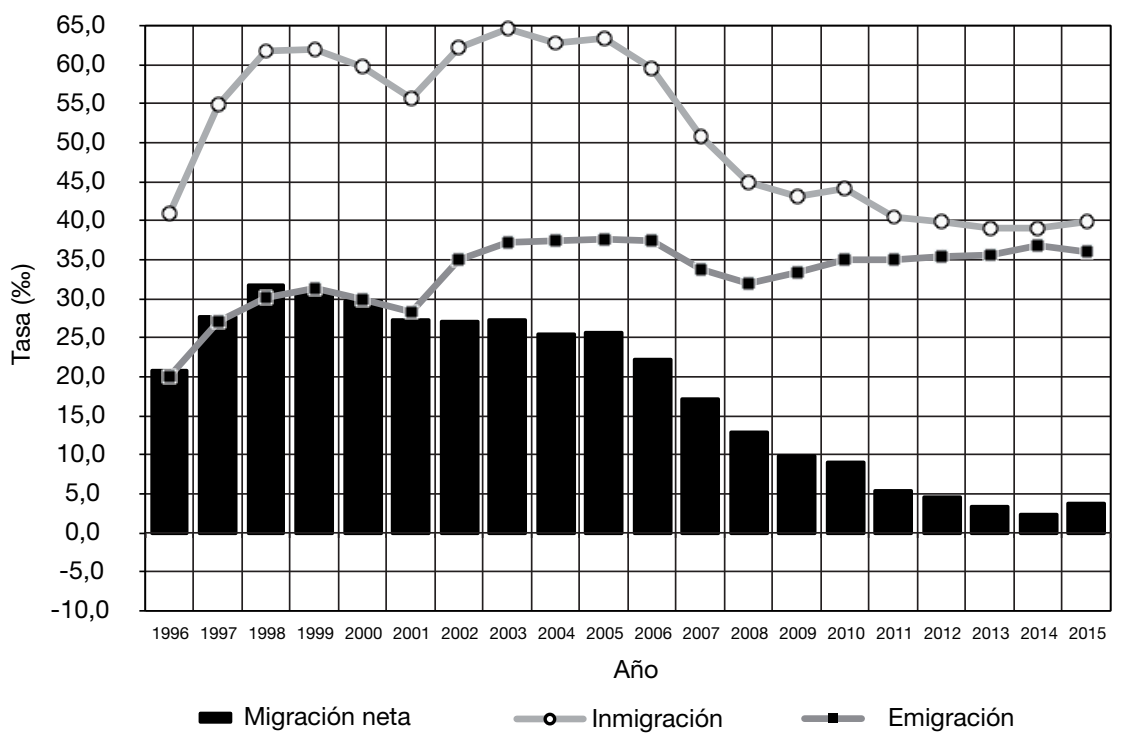

a) municipios compactos

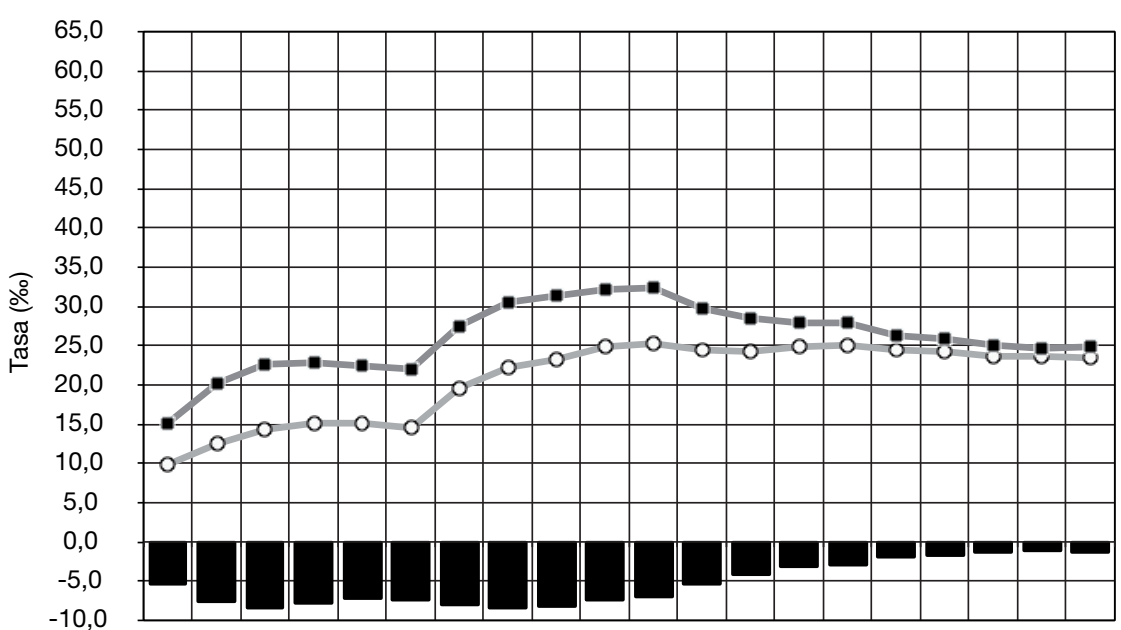

19961997199819992000200120022003200420052006200720082009201020112012201320142015

Año

$$
\text { Migración neta } \quad \text { - Inmigración Emigración }
$$

Fuente: elaboración propia a partir de INE: Estadística de Variaciones Residenciales 1996-2015. Fichero de microdatos. Padrón Municipal de Habitantes 1996 y Padrón Continuo 1998-2016. 
seguirá vigente durante décadas. Cabe destacar que la emigración desde estos municipios no muestra signos de incremento, sino que se mantiene anclada en torno a un moderado 35\% desde inicios del siglo XXI. A pesar de no aumentar su intensidad, sí se aprecia, en la composición de la emigración, el aumento de los flujos que se dirigen hacia poblaciones compactas (García Coll et al., 2016).

Paralelamente, cabe no olvidar lo que sucede en los municipios compactos (figura 3b), los cuales se sitúan en el lado opuesto. En ellos, se registran saldos migratorios negativos durante todo el período analizado, por lo que se convierten, de facto, en los principales emisores de los flujos migratorios con destino a poblaciones de baja densidad. La relación inversa entre el comportamiento migratorio de municipios compactos y dispersos y las tendencias opuestas seguidas entre ambos conjuntos (descenso de la emigración en los compactos, descenso de la inmigración en los dispersos) invitan a reflexionar sobre la percepción de los valores de la compacidad y la dispersión según nos encontremos en una etapa de ciclo económico alcista o en recesión (García Coll et al., 2016). López-Gay (2011) analiza la "vuelta al centro» que se apunta de forma incipiente en el caso de Barcelona. En un trabajo posterior, Bayona y López-Gay (2011) identifican muestras de convivencia temporal entre flujos de reurbanización y suburbanización. Cabe recordar también que, mientras la inmigración hacia municipios dispersos se reduce de forma drástica, la movilidad intrametropolitana en su conjunto disminuye levemente (figura 3). Así pues, más que un freno de la movilidad, se produce un reajuste metropolitano interno de la direccionalidad de los flujos (García Coll et al., 2016; Domínguez, 2014).

Además de su intensidad y del decidido patrón territorial seguido por la movilidad residencial hacia municipios dispersos, el tercer rasgo que agudiza su efecto es la composición desigual de los flujos que se desplazan hacia estas áreas, de manera que su efecto no actúa por igual en todos los estratos sociodemográficos. El perfil predominante de los actores de estos movimientos corresponde a parejas con hijos, rasgo habitual en esta modalidad residencial (Susino y Duque, 2013; Clark et al., 2015). De acuerdo con los datos de la encuesta realizada en 2005, tal y como se detallará en el epígrafe siguiente, se conoce que el $52 \%$ de las familias que se desplazan a vivir a una urbanización de la RMB son parejas con hijos y que casi tres cuartas partes corresponde a clases medias (un $43 \%$ son de clase media-alta y un 33\%, media), frente a un $13 \%$ de clase alta y un $7 \%$ de clase baja. La explotación de los registros de la EVR confirma este perfil migratorio marcado por el protagonismo de adultos jóvenes de 25 a 39 años acompañados de niños de 0 a 9 años (figura 4). En el caso de la RMB, destacan, también, las intensas tasas de migración de las personas de 75 y más años, las cuales varían de intensidad según el período de que se trate, en consonancia con el comportamiento de las edades centrales. Los movimientos de este grupo de edad cabría interpretarlos en clave de arrastre, ya que buscan una proximidad con sus hijos que migraron con anterioridad, bien para residir con ellos o bien en una vivienda propia pero cercana a la de sus descendientes (Smith et al., 2015). La opción de la institucionalización en 
Figura 4. Tasa de migración intrametropolitana por edad (\%) 2002-2007

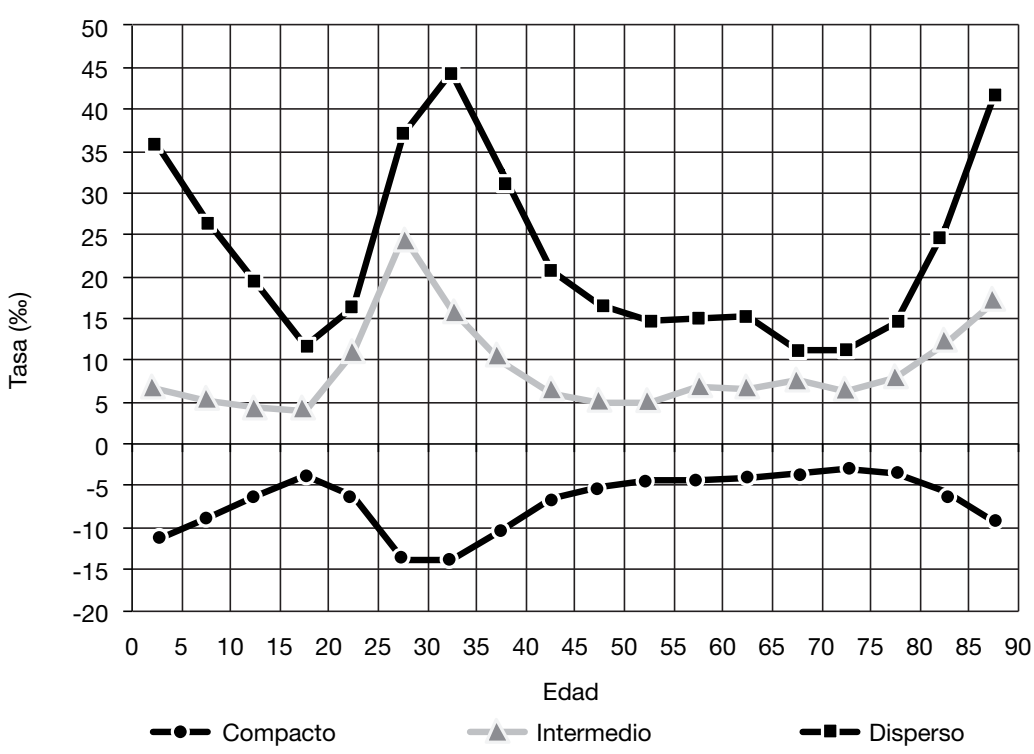

2008-2015

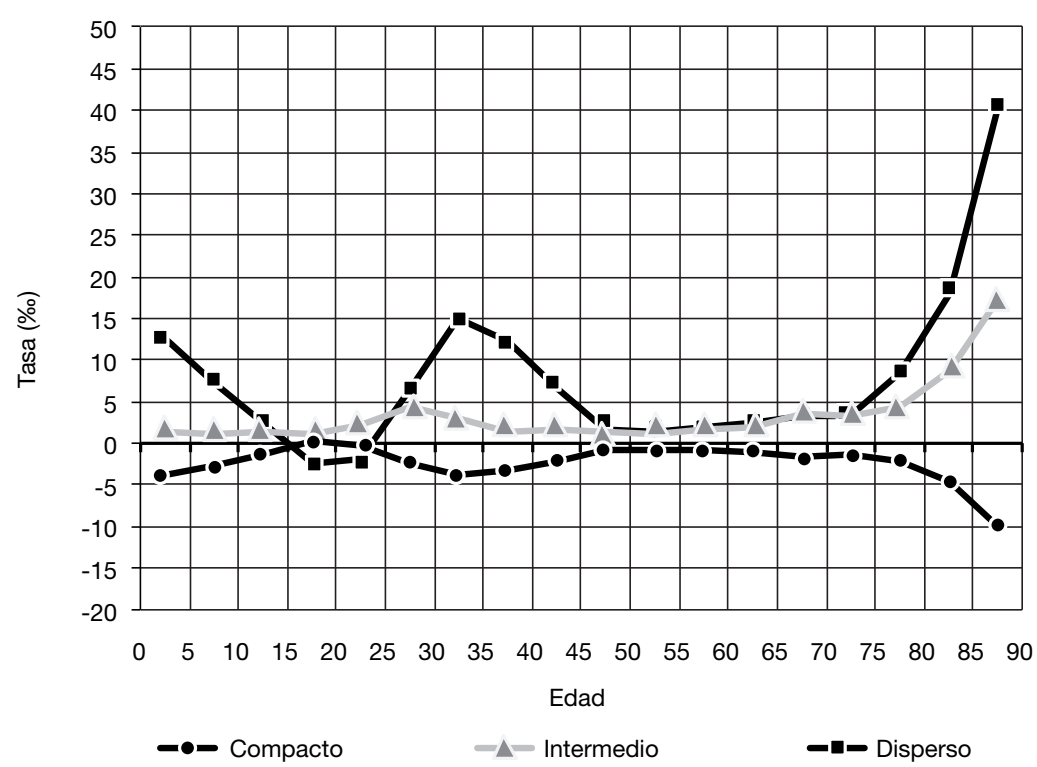

Fuente: elaboración propia a partir de INE: Estadística de Variaciones Residenciales 1996-2015. Fichero de microdatos. Padrón Municipal de Habitantes 1996 y Padrón Continuo 1998-2016. 
una residencia sería otra de las hipótesis, puesto que algunos de los municipios de baja densidad cuentan con una oferta de residencias para la tercera edad de alcance metropolitano (Pujadas et al., 2016; García Coll et al., 2016).

El patrón etario es similar para los períodos seleccionados (2002-2007 y 2008-2015). Las tasas son mucho más intensas en la etapa 2002-2007 para todas las edades, excepto para los mayores de 75 años. De la comparación de las tasas por edad del período precrisis y poscrisis, llama la atención el hecho de que, en las edades donde la migración hacia municipios dispersos es más baja, aparecen, por primera vez, índices netos de signo negativo o muy próximos a cero. Dicha circunstancia se nota en el período 2008-2015, tanto para el grupo de 15 a 24 años, para el que las tasas llegan a ser negativas, como en el caso de las edades comprendidas entre los 45 y los 64 años. Este comportamiento evidencia la importancia de la etapa vital y de las características familiares en la valoración de los beneficios de la residencia en disperso (Champion, 2001; García-Coll, 2014). Así, en el grupo de 55 a 64 años — que se aproxima a edades más avanzadas, con hijos mayores o bien ya emancipados-, el atractivo de la oferta residencial en disperso (tranquilidad, vivienda de gran tamaño, disponibilidad de jardín, etc.) sería menor, lo que explicaría ganancias migratorias prácticamente nulas. Lo mismo sucede en el caso de adolescentes o jóvenes, donde la lejanía respecto a la localización de centros educativos o de lugares de trabajo, el sobrecoste asociado al transporte que representa el residir en estos lugares o la dependencia paterna para el desplazamiento en el caso de los más jóvenes serían factores que jugarían a la contra de esta opción residencial.

Finalmente, para entender el fenómeno de la dispersión residencial, es necesario hacer referencia a las causas que generan este tipo de desplazamientos. Las migraciones hacia municipios de baja densidad constituyen una modalidad específica de movilidad residencial, en cuanto que los migrantes se desplazan a lo que se podría considerar la periferia de la periferia, principalmente urbanizaciones más o menos alejadas del núcleo urbano que se convierten en áreas de expansión residencial atractiva en la época del boom inmobiliario y de generalización de la suburbanización. En segundo lugar, disponen de abundante oferta de suelo a precio competitivo - en especial, si este se compara con municipios más densos-, hecho que permite adquirir viviendas de mayor superficie o con jardín y/o piscina a un amplio espectro social (Burriel, 2008). En tercer lugar, estas urbanizaciones se encuentran situadas en lugares de calidad ambiental elevada, característica especialmente apreciada por el perfil de residentes que optan por mudarse a las mismas. Sin embargo, trasladarse a una urbanización supone asumir también unas características que condicionan la vida cotidiana, como la ausencia de servicios básicos de proximidad, el sobrecoste económico de la vida en disperso o una gran dependencia del transporte privado (Henry, 2007). Pero la vida en una casa de una urbanización de este tipo también lleva asociados valores que positivizan y minimizan la percepción de posibles inconvenientes. Así, se aprecia su calidad ambiental, la posibilidad de brindar a los hijos espacios de juego al aire libre, de beneficiarse durante todo el año de las ventajas de áreas destinadas inicialmente para un uso vacacional y, en 
Figura 5. Motivo de la migración. Residentes en urbanizaciones de la RMB

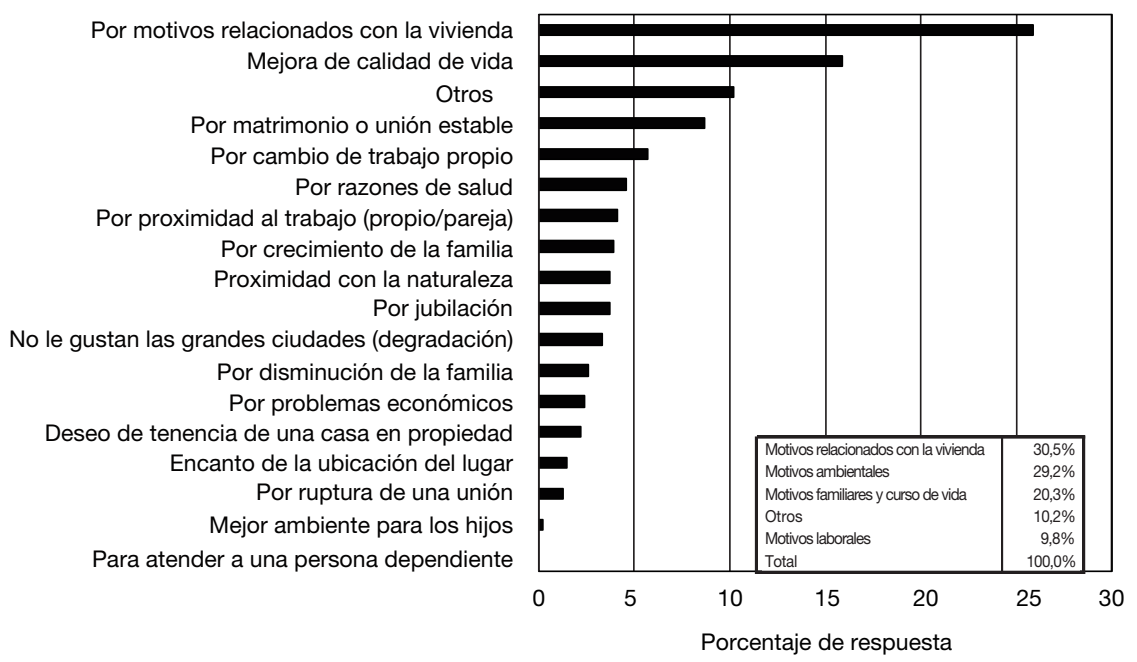

Fuente: encuesta Movilidad, solidaridad familiar y ciudadanía en la RMB, 2005.

ocasiones, incluso se asocia a una demostración de movilidad social ascendente que se visibilizaría a través de vivir en una casa y de las características de esta. En dicho contexto, la encuesta Movilidad, solidaridad familiar y ciudadanía en la Región Metropolitana de Barcelona muestra que el principal motivo que tienen los entrevistados para cambiar de residencia son los relacionados con el domicilio (un 30,5\%), así como con el entorno donde se vive (un 29,2\%) (figura 5).

Como se aprecia, los motivos puramente relacionados con las características del lugar donde se reside aparecen citados como los principales, muy por encima de otras causas como las laborales, las familiares, las relacionadas con la salud o las económicas. Por tanto, se trata de desplazamientos donde el componente puramente residencial desempeña un papel relevante en la toma de decisión de migrar.

Por lo que se refiere a los motivos para elegir una urbanización como lugar de destino de la migración, el argumento predominante es la búsqueda de tranquilidad y silencio (un 38\%), seguido de la consecución de una vivienda de mayor tamaño (un 16\%). En este caso, el hecho de tratarse de un entorno conocido (lugar donde residen familiares o amigos, ser segunda residencia o lugar de vacaciones) adquiere una cierta relevancia, al ser el motivo que justifica la elección del destino en casi uno de cada cuatro desplazamientos.

Lo cierto es que tanto los motivos por los que migrar como los que explican la elección del destino muestran estrategias residenciales altamente mediatizadas por necesidades o demandas propias de ciertas etapas vitales, pero que, 
Figura 6. Motivo de elección del destino de la migración. Residentes en urbanizaciones de la RMB

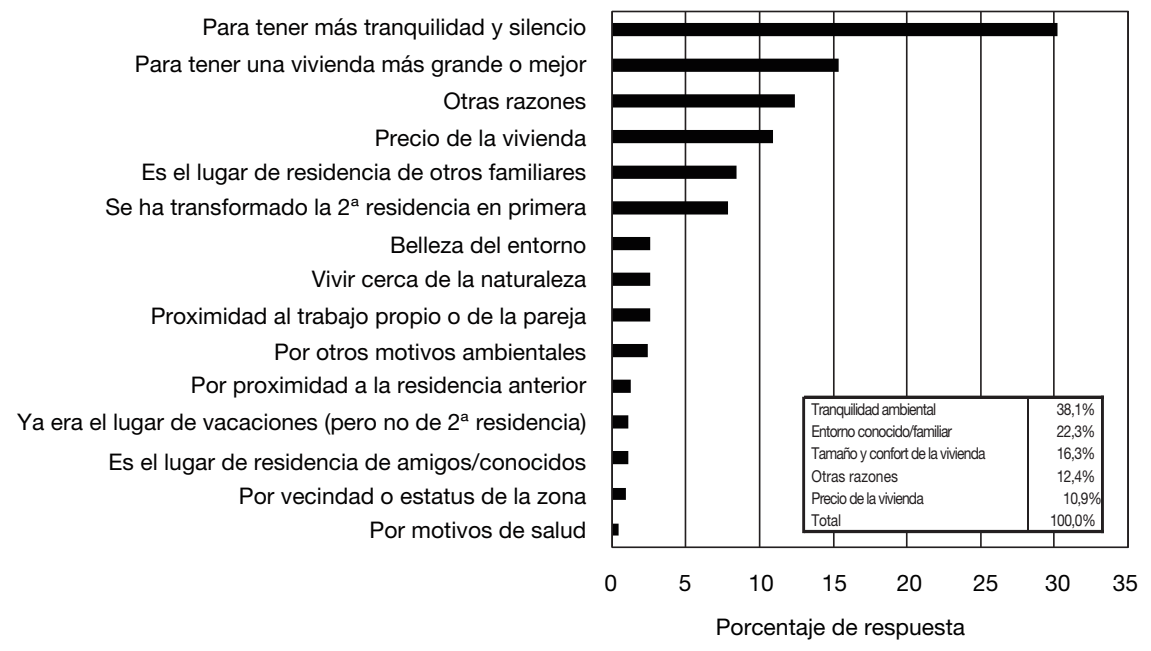

Fuente: encuesta Movilidad, solidaridad familiar y ciudadanía en la RMB, 2005.

en cambio, pueden estar sujetas a una percepción distinta a medida que se avanza en el curso existencial. Así, familias en fase de crecimiento y/o con hijos pequeños valoran viviendas más grandes con jardín o con espacios al aire libre. Por el contrario, el regreso a una situación de nido vacío, en caso de viudez, de ruptura de la pareja, de pérdida de autonomía a causa de la edad o de hijos jóvenes no independientes, definen situaciones que pueden alterar la percepción de los factores que, en el pasado, condujeron a esas personas a vivir en una urbanización (Champion, 2001; Richardson y Bae, 2004). Otro factor que no debe obviarse son los cambios producidos a raíz del inicio de la crisis. La coyuntura económica recesiva ha afectado a muchas familias, no solo en relación con los ingresos familiares, sino también en cuestiones tan fundamentales como las condiciones laborales o de lugar y de horario de trabajo. Otra consecuencia directa de la crisis ha sido la falta de inversión necesaria por parte de algunos ayuntamientos o de los propios vecinos en aquellas urbanizaciones que no se encuentran todavía recepcionadas, por lo que se retrasan algunas de las medidas de mejora que parecían inmediatas. Esta falta de inversión conduce a un empeoramiento de la calidad de vida, que, en ocasiones extremas, incluso deriva en una degradación de la misma (Burriel, 2015).

Existen, sin embargo, una serie de factores que siguen jugando a favor de esta opción residencial incluso en los momentos en los que la coyuntura económica se muestra más delicada. En primer lugar, buena parte de las urbanizaciones siguen conservando intactos los valores que explicaron su crecimiento en un pasado reciente: tranquilidad, entorno próximo a la naturaleza y una 
oferta residencial atractiva. En este último aspecto, incluso se aprecian mejoras sensibles, puesto que el estallido de la burbuja inmobiliaria ha contribuido a un descenso (o moderación) de precios y a un aumento de la oferta. Además, el incremento de vecinos que residen en ellas de forma habitual, la presión de las asociaciones que se organizan para defender los intereses de los residentes y la implicación de los ayuntamientos que han recepcionado las urbanizaciones y se han involucrado en su mantenimiento dan lugar a una mejora de las condiciones de vida en ellas. No obstante, el sobrecoste asociado a la vida en disperso y la lejanía de los servicios — que termina traduciéndose, finalmente, en más dinero y en más tiempo- son factores que tienen que ser asumidos por los que se deciden a trasladarse a dichos destinos.

El futuro de las migraciones hacia municipios dispersos muestra incógnitas. El sentido de su trayectoria se irá conformando a medida que evolucione el comportamiento de los diversos factores reseñados. No obstante, sea cual fuere el signo del futuro de las urbanizaciones, lo cierto es que el impacto de los movimientos experimentados en las últimas décadas ha generado una serie de cambios que condicionan la situación actual y su futuro más inmediato. A continuación, se presentan algunos de los rasgos más destacados de estas transformaciones y se reflexiona sobre los retos que significan.

\subsection{Hacia una nueva periferia. Transformaciones sociodemográficas de las áreas dispersas}

El desarrollo del urbanismo disperso en la RMB ha ido íntimamente ligado a un boom inmobiliario sin precedentes. Uno de los efectos inmediatos de la fiebre constructora unido a la demanda de vivienda ha sido la explosión demográfica que experimentaron los municipios dispersos. El acelerado incremento de la población implicó una profunda transformación de su estructura: las elevadas tasas de migración neta de población joven en edad reproductiva trajeron consigo un rápido proceso de rejuvenecimiento, al cual se sumó un potente crecimiento natural fortalecido por la pujante natalidad (Pujadas et al., 2013).

\subsubsection{El crecimiento de la actividad constructora}

La burbuja inmobiliaria, presente desde la década de 1980, se basó en un modelo urbanístico de expansión y consolidó un nuevo modelo de ciudad dispersa. Se desarrolló en un contexto de falta de planeamiento y de regulación urbanística unido a la voracidad de algunos municipios por atraer inversores y a la presión de las prácticas especulativas por parte de los promotores privados (Valdunciel, 2013). Estos procesos condujeron a una rápida recalificación de suelo rústico en urbanizable, lo que aceleró el crecimiento de la actividad constructora.

La intensidad de la actividad constructora fue creciente y alcanzó su cénit en el año 2006 —en 2005 en los municipios dispersos—, según evidencian las tasas de nueva construcción (licencias de obras iniciadas), para caer en picado a partir de 
Figura 7. Tasa de nueva construcción (licencias de obras iniciadas), 1999-2015

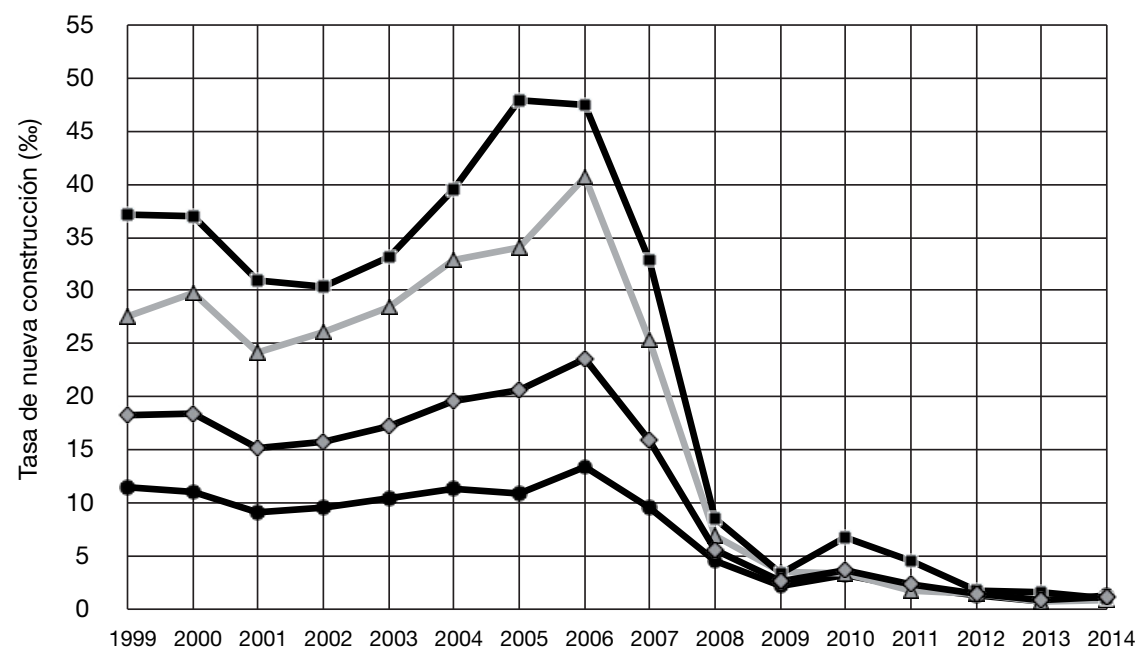

Año

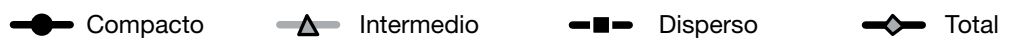

Fuente: elaboración propia a partir de colegios de aparejadores. Departamento de Territorio y Sostenibilidad. Generalitat de Catalunya: licencias de viviendas iniciadas y acabadas, e INE: censos de viviendas, 2001 y 2011.

ese momento, con lo que se anticipó al estallido de la crisis (figura 7). Los valores de las tasas de la media metropolitana ilustran la drástica reducción de la nueva construcción, que pasó de valores de un 23,58\% en 2006 a un 0,83\%o en 2013.

El mercado inmobiliario evidencia una clara preferencia por la dispersión residencial. Los valores más elevados de las tasas de nueva construcción se registraron en los municipios dispersos, donde se alcanzaron valores en torno a un $47,8 \%$ en el momento de máxima expansión. La intensidad de la nueva construcción se va debilitando conforme aumenta el nivel de compacidad, mostrando valores del 13,33\% en los municipios compactos en el mismo momento. Las diferencias territoriales en los valores de los índices de nueva construcción se reducen hasta la cuasi homogeneización a partir del año 2008.

Junto con la nueva construcción, cabe tener en cuenta la tipología edificatoria. Una de las características que define el urbanismo disperso en lo que a morfología residencial se refiere es el predominio de viviendas unifamiliares. La tasa de nueva construcción según la tipología edificatoria (viviendas unifamiliares) refuerza la intensa incidencia de la burbuja inmobiliaria en este tipo de municipios (figura 8). Durante los años anteriores a la crisis económica, la tasa de nueva construcción de viviendas unifamiliares en los municipios dispersos supera el 15\%o, y hasta 2005 esta tipología residencial rebasó el 38\% del total 
Figura 8. Tasa de nueva construcción (licencias de obras iniciadas) según la tipología edificatoria (viviendas unifamiliares), 1999-2015

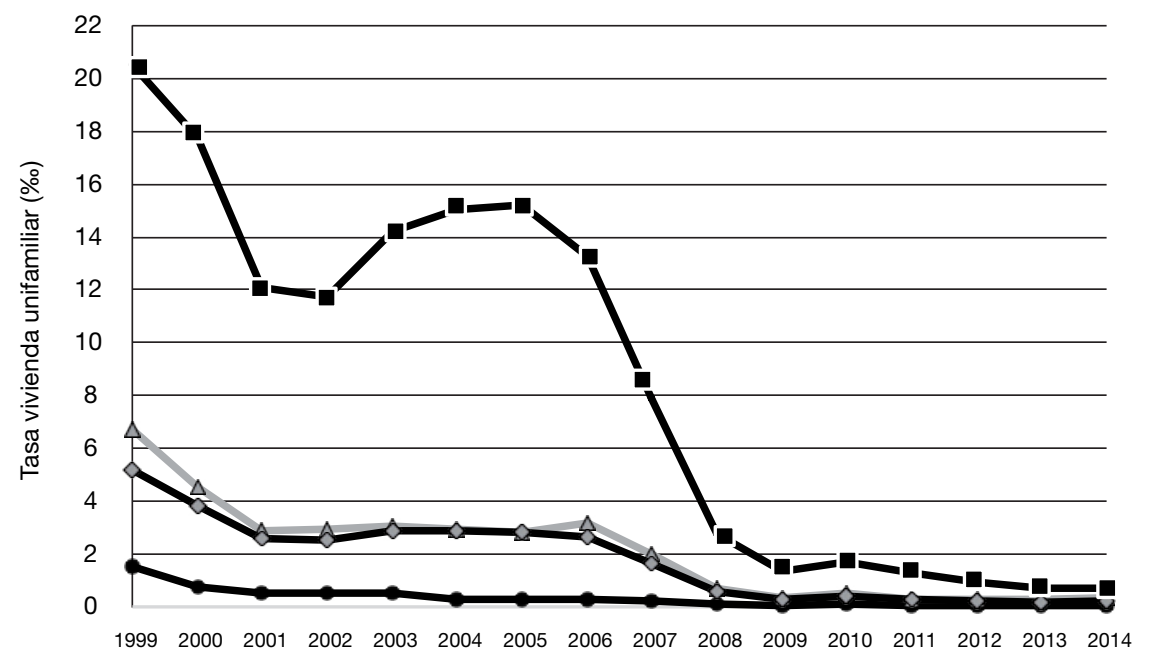

Año

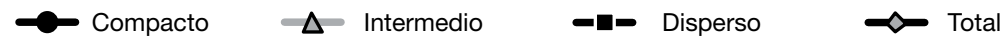

Fuente: elaboración propia a partir de colegios de aparejadores. Departamento de Territorio y Sostenibilidad. Generalitat de Catalunya: licencias de viviendas iniciadas y acabadas, e INE: censos de viviendas, 2001 y 2011.

de vivienda construida en municipios dispersos. La dinámica constructora de viviendas unifamiliares se frenó en seco ante la llegada de la crisis económica, presentó una leve desaceleración en 2006 y un desplome de tasas en 2007 y 2008, para colocarse, a partir de 2009 , en valores muy bajos en todo el territorio metropolitano. A pesar del cese de la actividad constructora, los municipios dispersos continúan encabezando la clasificación de las tasas de construcción de viviendas unifamiliares, aunque con valores inferiores al 2\%o a partir de 2012.

Con independencia de la recesión experimentada tras la crisis en la dinámica de nueva construcción, el intensísimo crecimiento, prolongado en el tiempo, permite consolidar la formación de una nueva periferia.

Diversos trabajos han abordado el tema en otras regiones españolas. GarcíaPalomares y Gutiérrez-Puebla (2007) identifican un proceso similar en el área de influencia de la ciudad de Madrid, basado, también, en un modelo único en el que la vivienda unifamiliar tiende a homogeneizar los paisajes, reducir las densidades metropolitanas y acrecentar la fragmentación espacial. Muñoz (2010) se refirió a este proceso con la palabra urbanalización, puesto que consideró que la tipología constructiva y las formas de ocupación del espacio se reproducen entre las diferentes promociones, lo que da lugar a una originalidad 
escasa que banaliza el territorio, aunque la aparente homogeneidad va desapareciendo según la categoría socioeconómica de los habitantes que ocupan las áreas residenciales dispersas.

En el caso de la Región Metropolitana de Barcelona, Catalán et al. (2008) estiman que casi un tercio de la expansión del suelo urbano entre 1993 y 2000 se destina a uso residencial disperso, tipología que representa, en el año 2000, un $27 \%$ de suelo urbano metropolitano y un $5 \%$ del total. Según los datos de la encuesta Movilidad, solidaridad familiar y ciudadanía en la RMB, las características de las viviendas del urbanismo disperso en la RMB mostraban que el $89,6 \%$ de la tipología de la vivienda de las urbanizaciones era unifamiliar; el $45,3 \%$ contaba con una superficie superior a los $150 \mathrm{~m}^{2}$; el $59 \%$ del parque residencial fue construido a partir de 1985 (un 31,3\% a partir de 1995), y, en relación con la tenencia, el $48,2 \%$ de las viviendas se encontraba en régimen de propiedad pendiente de pago.

En definitiva, un contexto residencial en contraste con la ciudad compacta y que presenta las características siguientes: en entornos naturales, con viviendas unifamiliares, más grandes, más nuevas y en régimen de propiedad aunque con hipotecas pendientes. Frente a entornos densos, con edificios con varias viviendas, las cuales, en una proporción superior al 83,3\%, tienen superficies menores a los $100 \mathrm{~m}^{2}$ y más de las dos terceras partes fueron construidas antes de 1975, con la diferencia de que la mitad de ellas están en régimen de propiedad totalmente pagada.

El estado de la propiedad (totalmente pagada o pendiente de hipoteca), entre otros aspectos relacionados con la vivienda (costes derivados del mantenimiento, de los desplazamientos y la dependencia del vehículo privado, así como la ausencia de equipamientos y servicios), sitúan a las poblaciones residentes en este tipo de hábitat en una situación de vulnerabilidad que se intensifica con la irrupción de la crisis económica (López Villanueva et al., 2016).

\subsubsection{Un crecimiento demográfico explosivo y un cambio estructural}

Una de las consecuencias de la movilidad residencial hacia los municipios dispersos ha sido el también boom demográfico. Los municipios dispersos no solo han experimentado un crecimiento explosivo en un lapso de tiempo muy breve, sino que también han sufrido una profunda transformación en la estructura de la población.

El crecimiento ha sido especialmente visible en un contexto de baja expansión metropolitana y en un marco con una tipología residencial muy homogénea (viviendas unifamiliares), con lo que ha llegado a producirse una especialización del territorio (Módenes, 2012) que la llegada del nuevo ciclo económico ha detenido y transformado.

En 2015, 714.036 personas residían en municipios con predominio de hábitat disperso. Aunque esta cifra supone tan solo el 14,2\% de los habitantes del área metropolitana, el crecimiento intensísimo experimentado hasta 2008 ha dejado una enorme huella en la estructura de la población y en su evolución futura. 
Figura 9. Evolución de la población. Municipios dispersos (1996-2015)

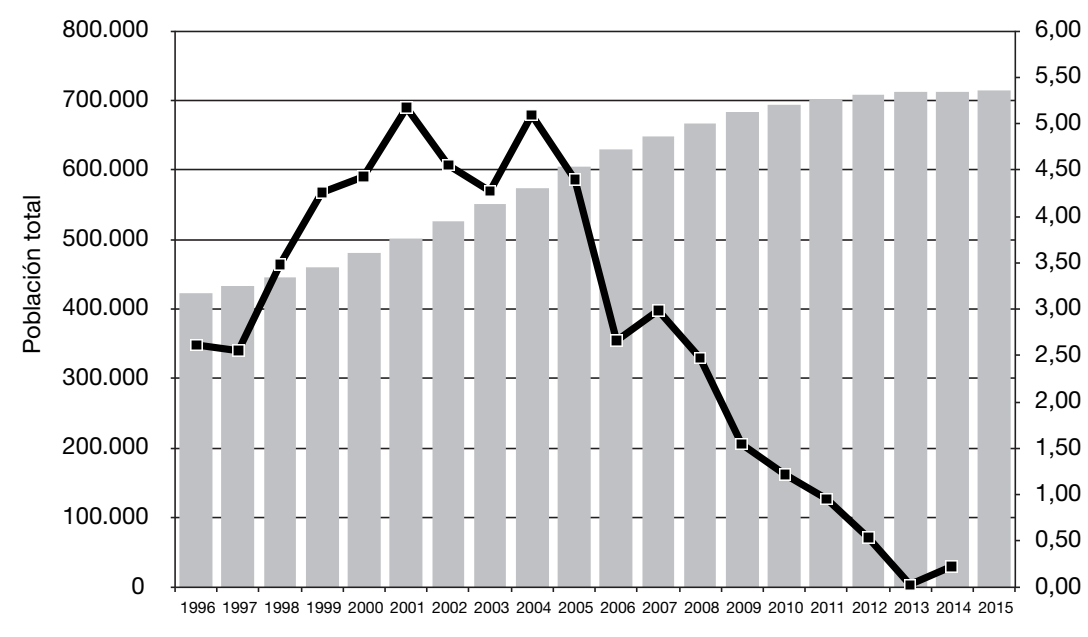

Año

Fuente: elaboración propia a partir de INE: Padrón Municipal de Habitantes 1996, y Padrón Continuo 1998-2015.

La primera cuestión a destacar es el potente crecimiento experimentado entre 1991 y 2015. La población residente en los municipios dispersos se duplicó, puesto que pasó de los 351.340 individuos a los 714.036 habitantes actuales (figuras 9 y 10). El crecimiento más intenso se produjo en tan solo siete años - entre 1999 y 2006-, cuando la población creció en un 37\%, con lo que rebasó el $4 \%$ anual, tasa que algunos municipios superaron con creces. El potente crecimiento migratorio protagonizado por parejas jóvenes en edad reproductiva contribuyó a facilitar un intenso crecimiento natural con índices superiores al 13\%o, lo que cambió con celeridad la composición de las poblaciones de estos municipios.

A partir del año 2006, una vez más anticipándose al estallido de la crisis, la tasa de crecimiento poblacional se redujo a la mitad, puesto que pasó de un $4,40 \%$ a un $2,66 \%$ y se debilitó hasta registrar valores próximos a 0 a partir del año 2010.

A la dinámica expansiva, le sigue una etapa en la cual la actividad constructora se para, la dinámica migratoria se frena y el incremento natural se detiene. Como consecuencia de todo este conjunto de cambios, el crecimiento de la población cesa, lo cual altera las estructuras demográficas que se habían transformado en profundidad en la época de gran crecimiento (figuras 11, 12 y 13). La mayoría de estos municipios debieron plantearse un cambio drástico en la gestión municipal, puesto que, en muy poco tiempo, algunos de ellos dupli- 
Figura 10. Crecimiento de municipios dispersos. Comparación con otras tipologías municipales $(1996=100)$

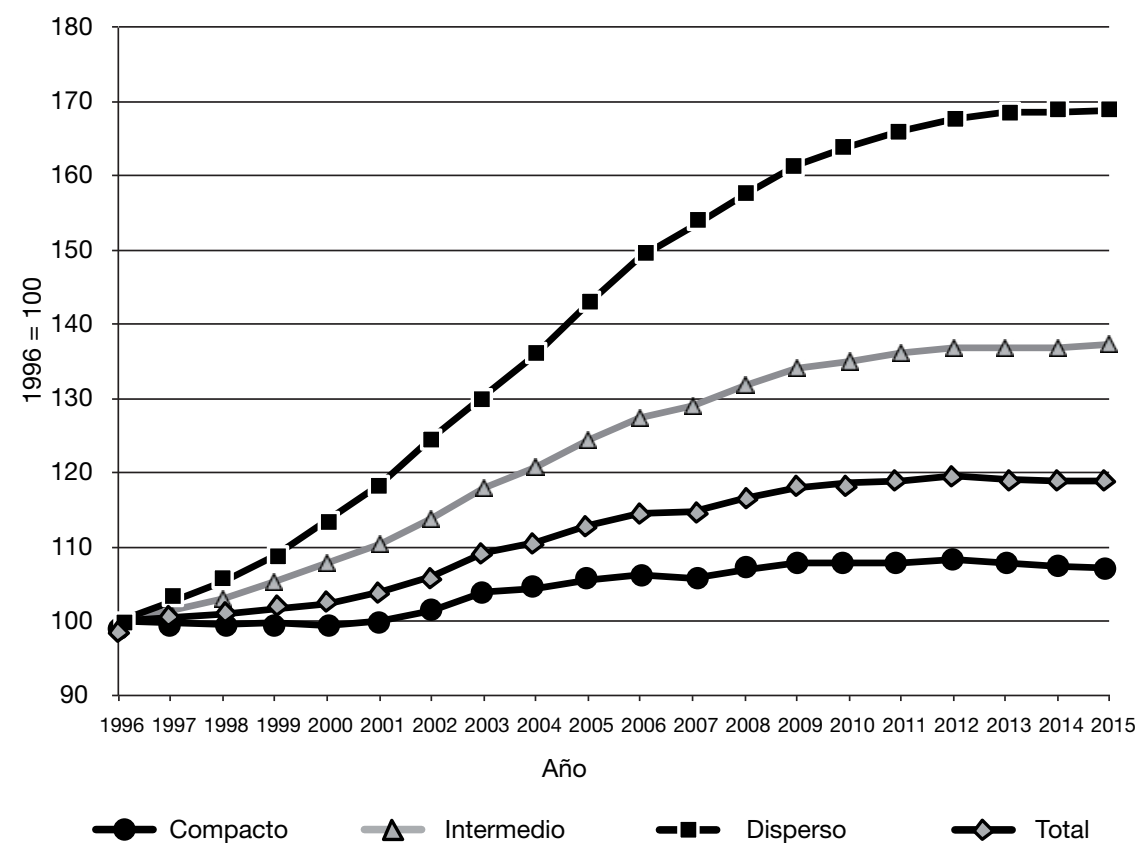

Fuente: elaboración propia a partir de INE: Padrón Municipal de Habitantes 1996 y Padrón Continuo 1998-2015.

caron sus efectivos y no de manera homogénea en lo que a edades se refiere. A la tensión generada por la demanda de equipamientos y servicios derivados de esta población en crecimiento y con gran potencial expansivo, le sigue una nueva etapa, en la cual hay que hacer frente a nuevas necesidades derivadas de una migración mucho menos intensa y de un crecimiento mucho más débil.

Antes de la irrupción de la crisis económica, la estructura por edades de la población mostraba una amplia proporción de población infantil, que pasó del 17,23\% en 2002 hasta llegar a alcanzar el 22\% en 2008 (casi uno de cada cuatro habitantes del disperso tenía menos de 15 años), en oposición con el exiguo porcentaje de población de esta edad del compacto, con casi ocho puntos porcentuales de diferencia en 2008. En el lado opuesto, la población mayor de 65 años representaba, en 2002, tan solo el 13,17\% del total de la población de los municipios dispersos, con más de 5,2 puntos porcentuales por debajo de la población residente en municipios clasificados como compactos (un 17,90\% en 2008 y un $19,82 \%$ en 2015). Se trataba, pues, de una estructura joven con importante potencial de crecimiento, como así lo mostraba la evolución entre los años 2002 y 2006. 
Figura 11. Estructura por sexo y edad. Municipios compactos y dispersos, 2002

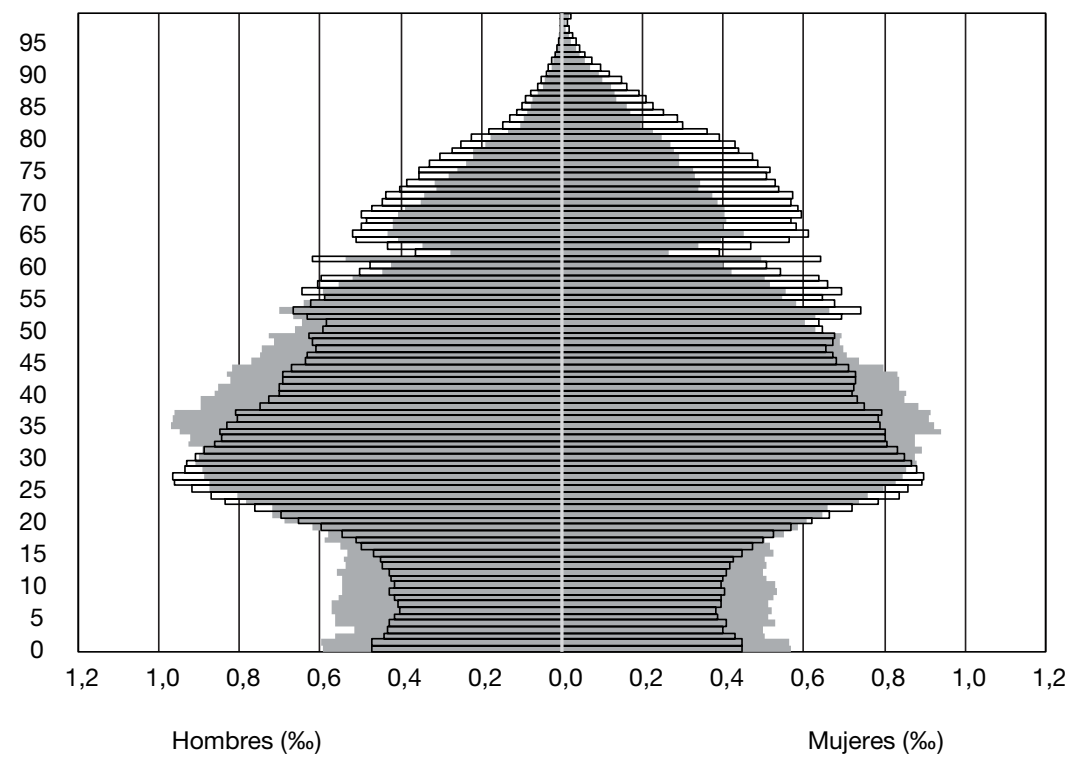

— Población municipios compactos

Fuente: elaboración propia a partir de INE: Padrón Continuo 2002.

Esta composición reflejaba el predominio de una estructura de familias formada por parejas con hijos menores - tal y como arrojaron los datos de la encuesta Movilidad, solidaridad familiar y ciudadania en la $R M B$-, donde el $51,83 \%$ de los hogares presentaba esta tipología, seguidos del 27,3\% formado por los hogares de parejas sin hijos (Alabart y López Villanueva, 2007). El resto de tipos de domicilios, como los monoparentales o unipersonales, poco acordes con un modelo residencial disperso, se situaban en una posición residual.

Esta evolución se interrumpe con cierta anticipación al estallido de la crisis: se ralentiza la intensidad migratoria que, desde 2005, había ido modificando la estructura por edades de la población, frenando el crecimiento y reteniendo el rejuvenecimiento. De esta manera, la proporción de población menor de 16 años se reduce del 22\% del año 2008 al 19,2\% del año 2015 y la población mayor de 65 años se mantiene en un 15\%, con un aumento de 2 puntos porcentuales desde 2002 (figuras 11, 12 y 13). Si entre 2002 y 2008 era la población infantil la que había presentado un mayor crecimiento (los menores de 5 años pasaron de ser 28.934 a ser 45.018), entre 2008 y 2015 la población de esa edad perdió 6.844 individuos (figuras 14 y 15). La población mayor de 65 años se incrementó de 69.417 personas en 2002 a 107.106 en 2015, con lo que se inició un progresivo envejecimiento que la migración o la natalidad no han logrado revertir. 
Figura 12. Estructura por sexo y edad. Municipios compactos y dispersos, 2015

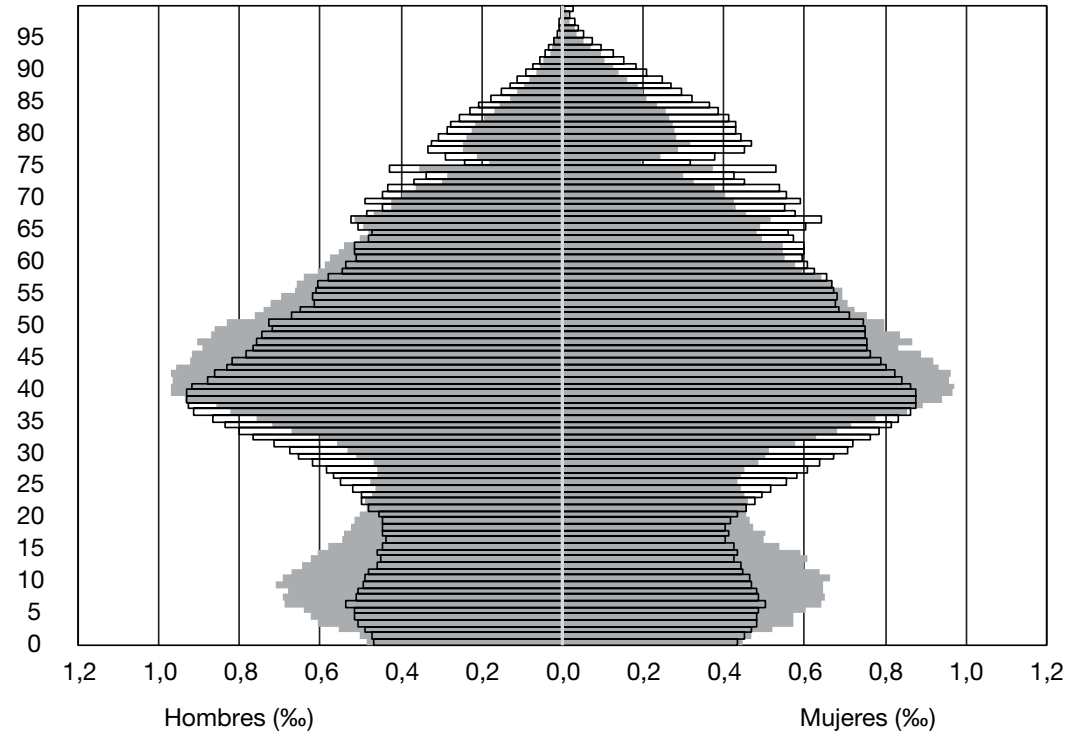

Población municipios compactos

Fuente: elaboración propia a partir de INE: Padrón Continuo 2015.

Figura 13. Estructura por sexo y edad de los municipios dispersos, 2002 y 2015

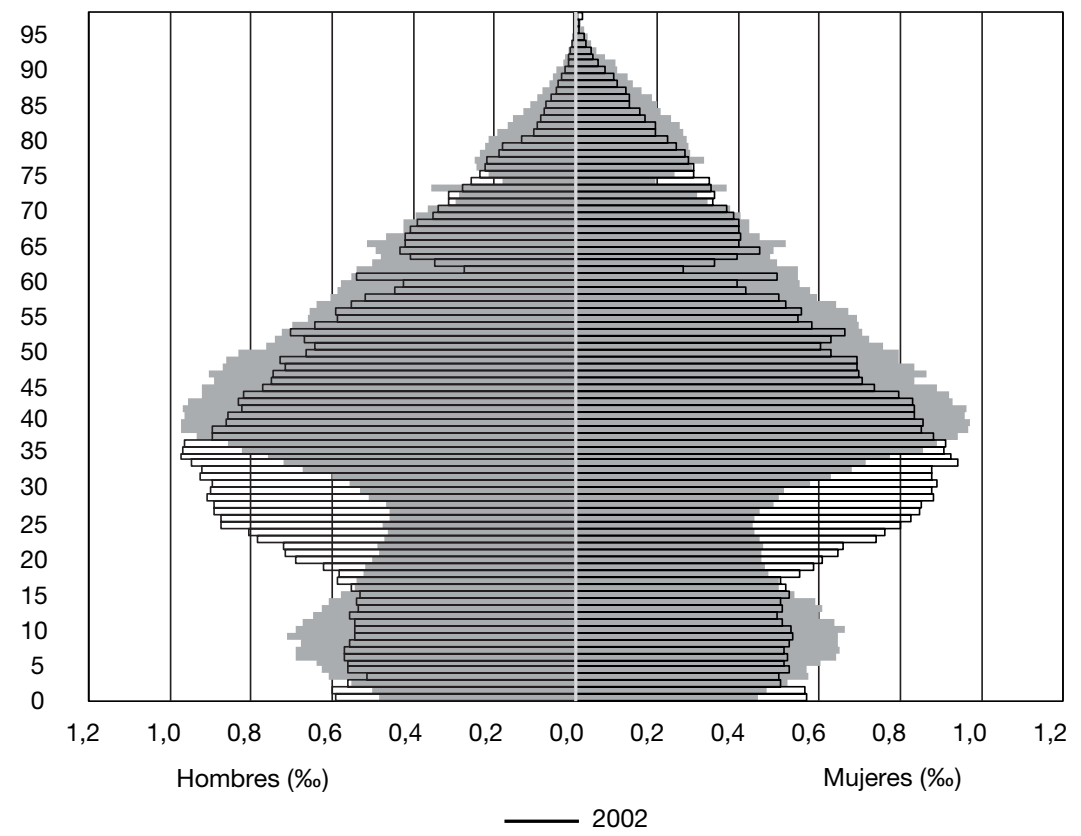

Fuente: elaboración propia a partir de INE: Padrón Continuo 2002 y 2015. 
Figura 14. Cambio estructural en el período 2002-2008. Variación absoluta por edades simples

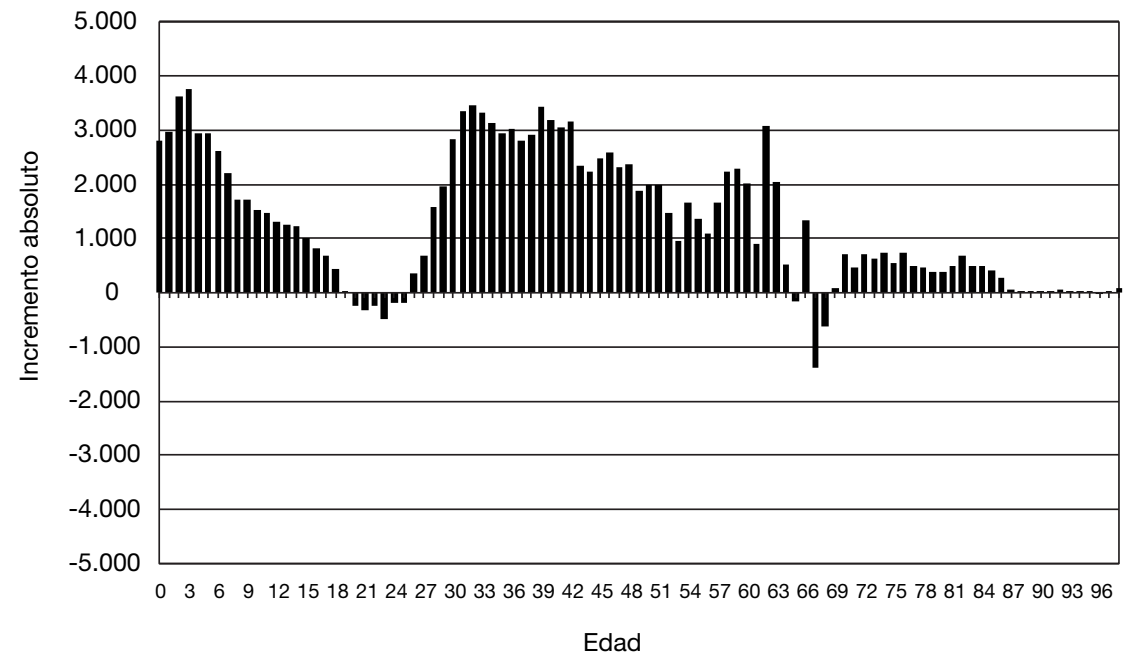

Fuente: elaboración propia a partir de INE: Padrón Continuo 2002 y 2008.

Figura 15. Cambio estructural en el período 2008-2015. Variación absoluta por edades simples

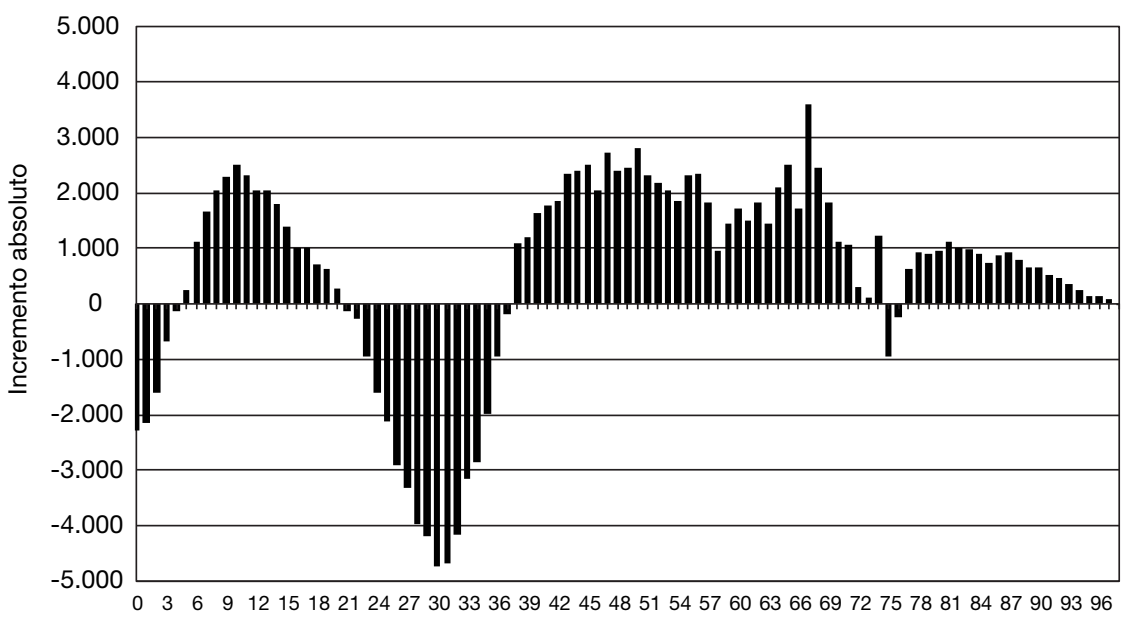

Edad

Fuente: elaboración propia a partir de INE: Padrón Continuo 2002 y 2015. 
De este cambio de tendencia en la dinámica y en la estructura de la población, se desprenden varias cuestiones: si bien es cierto que este tipo de modelo residencial ha estado protagonizado de manera acentuada por parejas jóvenes con hijos menores, cabe preguntarse si la vida en disperso es adecuada para otras fases del ciclo de vida familiar, y qué sucede cuando los hijos crecen y se emancipan. La crisis económica ha podido enmascarar este efecto, puesto que ha podido frenar cambios de residencia e incluso retener a los hijos en los hogares de referencia ante la dificultad de vender y de obtener créditos hipotecarios.

Estas nuevas tendencias en la dinámica y en la estructura demográficas plantean nuevos retos para la gestión local, que se desarrolla en un contexto de estancamiento y con las arcas municipales mermadas (Hortas-Rico, 2014; Gielen, 2016).

\subsubsection{Transformación social}

A lo largo del texto, se ha ido caracterizando la población que reside en disperso. La encuesta Movilidad, solidaridad familiar y ciudadania en la $R M B$, de 2005, y fuentes complementarias, como el Servicio de Información Económica Municipal, arrojan datos acerca de cómo se perfila la población y de cómo se ha ido produciendo la transformación social en estas nuevas periferias. Siguiendo la encuesta anteriormente citada, los protagonistas de la movilidad residencial fueron personas jóvenes, entre 25 y 45 años, provenientes mayoritariamente de Barcelona y del resto de su región metropolitana, y el 57,50\% llegó al domicilio

Figura 16. Evolución de la renta per cápita. Municipios de la RMB 2000-2015

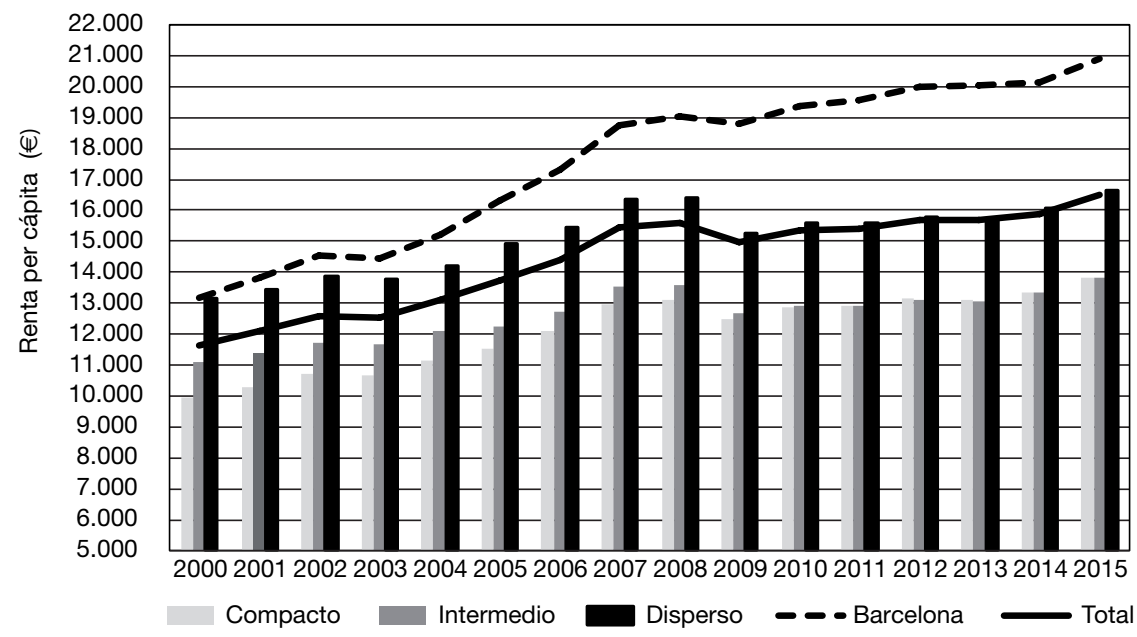

Fuente: elaboración propia a partir de la renta bruta familiar disponible. Servicio de Información Económica Municipal (SIEM) de la Diputación de Barcelona. 
de la urbanización a partir de 1996. Con un nivel de instrucción medio-alto (casi el $40 \%$ tenía estudios medios y más del 30\%, estudios universitarios), se trataba de una población activa (más del 60\% estaban ocupados) donde predominaban los altos técnicos (más del 18\%) y con vivienda en propiedad aunque pendiente de pago (el 48,2\%).

En cuanto al estrato social al que pertenecen los residentes, los resultados de la encuesta muestran que una más que holgada mayoría pertenece a la categoría socioeconómica media. En concreto, el grupo mejor representado corresponde al de categoría media-alta, que significa un $43,5 \%$ del total de residentes.

El análisis de la evolución de la renta per cápita evidencia la situación privilegiada de la población que reside en municipios con alta presencia de dispersión urbana. A excepción hecha de la ciudad de Barcelona, que se ha tratado de manera aislada por su evolución particular, los municipios dispersos de la RMB registran las rentas más elevadas respecto al resto del territorio y se mantienen como la categoría municipal con mayores ingresos (figura 16).

A pesar de registrar ingresos familiares y per cápita superiores al promedio de la RMB, a partir del año 2009, las diferencias se reducen hasta registrar valores muy similares, lo cual evidencia que el descenso del nivel de renta fue superior a la media metropolitana y que su recuperación posterior fue más lenta.

Figura 17. Evolución de la renta en los municipios dispersos según nivel de renta (año $2000=100$ )

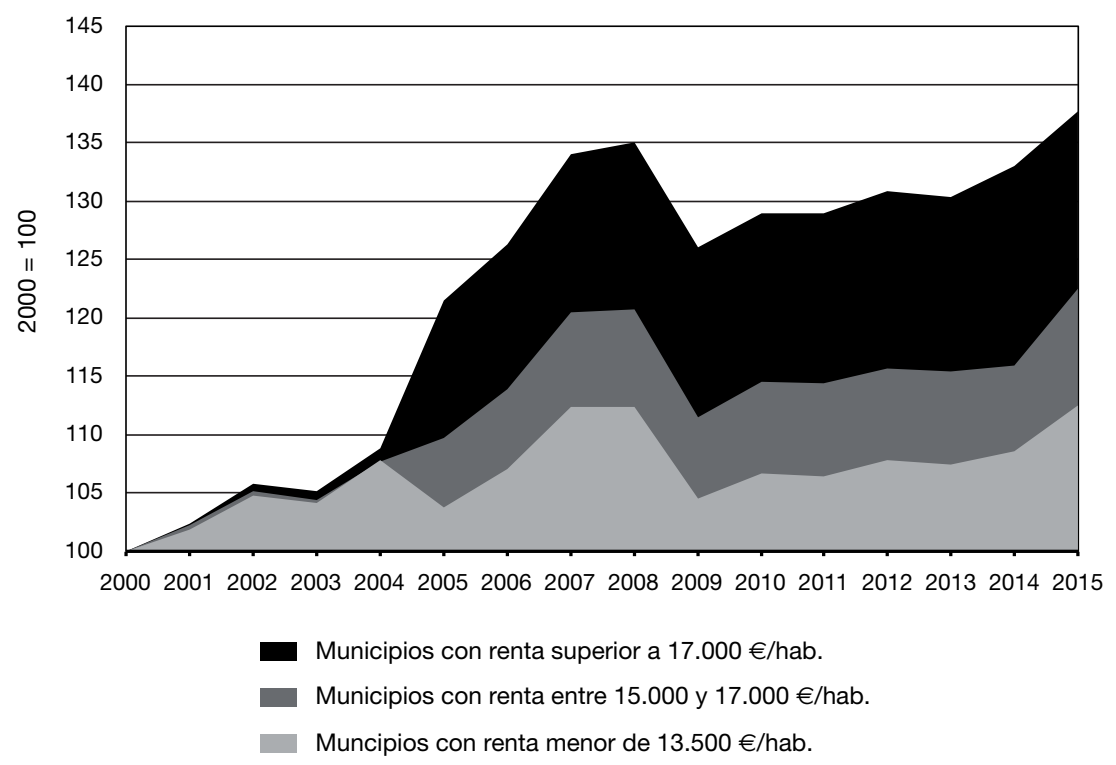

Fuente: elaboración propia a partir de la renta bruta familiar disponible. Servicio de Información Económica Municipal (SIEM) de la Diputación de Barcelona. 
La ciudad de Barcelona es el municipio que, con gran diferencia, mejor resiste el impacto de la crisis, con pérdidas de renta muy débiles y con una recuperación mucho más intensa que el resto del territorio (con lo que arrastra a la media metropolitana), lo que provoca un fuerte distanciamiento del resto de los municipios de la RMB (a partir ya del año 2000) y pone de manifiesto la hegemonía notoria de la ciudad central en cuanto a concentración de rentas elevadas.

Sin embargo, cuando se analiza el nivel de renta per cápita de los municipios dispersos según tramos de ingresos (figura 17), se observa una evolución muy diferenciada entre los que cuentan con rentas elevadas en relación con los que muestran menores ingresos.

Las rentas per cápita de los 28 municipios que, en 2015, ostentan valores superiores a los 17.000 euros por habitante crecen a partir de 2004 con una gran celeridad y se mantienen siempre muy por encima del resto de municipios dispersos, incluso a partir de 2008, con el estallido de la crisis, donde la recuperación se aprecia más intensa. Esta tendencia se relaciona con las tesis de Marí-Klose y Martínez Pérez (2015), quienes señalan que la crisis no solo ha significado un ensanchamiento de la brecha entre clases medias y altas, sino que también ha llevado a una cierta polarización interna de las clases medias, estrechamente relacionada con la desigualdad salarial.

\section{Conclusiones}

La revisión del proceso de dispersión residencial en la RMB ha puesto de manifiesto la capacidad transformadora de la movilidad cuando, como sucede en este caso, se produce de forma tan intensa y con unos patrones sociodemográficos tan específicos. Este artículo ha analizado quién se ha desplazado a los municipios de baja densidad en la RMB —en los que las urbanizaciones tienen un relevante protagonismo- $-y$ por qué, a la búsqueda de profundizar en las raíces de dicho proceso. A su vez, se ha demostrado su impacto en la construcción, en el volumen y en la estructura de su población, al igual que en su componente social. El resultado muestra cómo se ha forjado una nueva periferia residencial, más urbanizada, más poblada y con nuevos retos a afrontar.

A pesar de que el fenómeno de la dispersión residencial se ve truncado con la llegada de la crisis económica, incluso un poco antes a resultas de una aparente saturación del modelo, la huella de lo sucedido en un pasado inmediato es suficientemente profunda como para haber marcado su trayectoria definitivamente.

El intenso crecimiento experimentado por la población significa un aumento de la presión sobre la demanda de servicios y de equipamientos, de necesidades diversas a las que los responsables municipales deben dar respuesta y que, de hecho, contribuyen a transformar las dinámicas comerciales, asociativas e incluso políticas (equipos de gobierno municipal) a escala local. El sobredimensionamiento de las cohortes que ocupan edades más proclives a este tipo de estrategia residencial modifica la estructura demográfica de los municipios 
receptores. Así, en un primer momento, la llegada de adultos en edades centrales con menores (o en edad de ser padres) rejuvenece su estructura. Pero, con el paso del tiempo, estas generaciones complementadas por la inmigración van avanzando en la pirámide y modulan las necesidades y las demandas en función del grupo etario donde se sitúan. Así, en 2015, su presencia en las pirámides se aprecia en unos nutridos grupos de edad de entre 40 y 59 años — sobre todo entre 40 y 49-, así como de menores de 20 -especialmente entre 5 y 15 años-, hijos de los anteriores. Igualmente, pese a ser pirámides mucho menos envejecidas que las de los municipios compactos, sí se aprecia en ellas el engrosamiento del grupo de mayores producido entre 2002 y 2015 , consecuencia del flujo de entrada de personas de edad avanzada identificado a través del análisis migratorio.

La sobrerrepresentación en estos flujos de clases medias-altas (un 43\%) y altas (un 13\%) contribuye a una cierta elitización, la cual se aprecia a través de la renta familiar, que, en estas poblaciones, es superior al promedio metropolitano. Si bien es cierto que la evolución reciente de la renta media familiar del conjunto de municipios dispersos muestra su progresiva aproximación al promedio de la RMB, también lo es que, cuando se compara la evolución de este indicador diferenciando tramos de renta, se observa la fuerte correlación entre nivel de renta y crecimiento de la misma. En definitiva, la segregación social se acentúa como consecuencia de la movilidad residencial, donde el precio de la vivienda actúa como filtro efectivo que retroalimenta el proceso. Además de esta tendencia, cabe tener en cuenta la posible brecha socioeconómica entre autóctonos y nuevos residentes o la expulsión de residentes tradicionales (o sus hijos) a causa del incremento del precio de la vivienda, que aparecen como fenómenos sociales emergentes.

El urbanismo disperso presenta una problemática medioambiental asociada al consumo extensivo de espacio, una excesiva urbanización del territorio sobre todo de espacios naturales, que notan la presión de su transformación a uso residencial-, un mayor consumo de energía o su gran dependencia del transporte privado. Sin embargo, el reto social de este cambio urbano se encuentra en dar respuesta a las nuevas necesidades que, además, serán cambiantes conforme vaya pasando el tiempo y las generaciones envejezcan. Las estrategias de cohesión social y de integración de los nuevos residentes, en definitiva, de convertir las urbanizaciones en un barrio más de los municipios a los que pertenecen, se combinan con la necesidad de evitar la degradación de aquellos espacios de mayor fragilidad socioeconómica o la fractura fruto de la segregación en aquellos donde residen las familias con rentas más altas.

La reflexión sobre el futuro de los municipios dispersos de la RMB obliga a dirigir la mirada hacia dos direcciones. Por un lado, como se ha venido comentando, la necesidad de gestionar la herencia dejada por la etapa del boom migratorio, cuyo impacto es conocido y, por tanto, más previsible. En cambio, se abre un abanico de posibilidades cuando se considera el posible futuro de la movilidad con destino a municipios dispersos. De una parte, estos conservan su atractivo, que conecta estrechamente con una opción residencial presente 
en el imaginario deseado por muchas familias. De otra, el papel de las cadenas migratorias puede ampliarse, de manera que se intensifiquen desplazamientos siguiendo estrategias de aproximación de familias o amigos. A estos aspectos que podrían favorecer la recuperación de la movilidad residencial con destino a municipios dispersos, se les suma la existencia de una oferta de vivienda, ahora, a precios muy competitivos por la falta de demanda y de promotores inmobiliarios con expectativas de que una recuperación económica y una mejora en las condiciones de acceso a los préstamos hipotecarios les permitan retomar una actividad similar a la del boom inmobiliario.

Por otro lado, las severas restricciones económicas que la crisis ha provocado en un porcentaje elevado de familias, la entrada en etapas del curso de vida donde el atractivo residencial de estas zonas es menor por parte de los nuevos residentes que llegaron con la expansión de la dispersión residencial, el fracaso a la adaptación a la vida en disperso o la imposibilidad de asumir el sobrecoste de habitar estas áreas son factores que podrían actuar promocionando su abandono. También cabe tener en cuenta que estas mismas restricciones económicas pueden actuar bloqueando los cambios deseados de domicilio, puesto que la marcha viene condicionada por la necesidad de vender la casa donde se reside.

En estos momentos, cuando los saldos migratorios intrametropolitanos de los municipios dispersos son prácticamente nulos, resulta difícil pensar la pervivencia de unas estrategias residenciales que los convirtieron en destinos preferentes. La posibilidad de retomar un crecimiento positivo tendría que ir de la mano de la vuelta de una etapa de bonanza económica y de la reactivación del dinamismo del mercado de la vivienda, que, hoy por hoy, parece lejano. No obstante, sea cual fuere el caso, cabe tener en cuenta cuál ha sido la experiencia, tanto en el campo de la planificación urbanística como en la gestión municipal, para poder evitar la repetición de los errores del pasado.

\section{Referencias bibliográficas}

AlABART, A. (2007). «Mobilitat residencial, solidaritat familiar i ciutadania a les regions metropolitanes». Revista Catalana de Sociologia [en línea], 10, 23-39. $<$ http://dx.doi.org/10.2436/20.3005.01.11>.

Alabart, A.; GaValdȦ, J. y VilÄ, G. (2010). «Consecuencias urbanas de las recientes dinámicas económicas: Análisis de áreas prototípicas de la RMB». Ponencia presentada en el VIII Congreso Vasco de Sociología. Bilbao, 10-12 de febrero.

Alabart, A. y López Villanueva, C. (2007). «Familias, hogares y viviendas en las regiones metropolitanas: El caso de Barcelona». Cadernos Metropole, 17, 81-102.

AlabART, A. y VILȦ, G. (2007). «Territori i estructura social a Catalunya». En: ACS. La societat catalana. Barcelona: Associació Catalana de Sociologia. Institut d'Estudis Catalans, 177-202.

Barba, J. y MerCADÉ, M. (2006). Les urbanitzacions a la provincia de Barcelona: Localització i característiques dels sistemes de baixa densitat residencial. Barcelona: Diputació de Barcelona. 
BAYONA, J. y GIL, F. (2008). «El papel de la inmigración extranjera en la expansión de las áreas urbanas: El caso de Barcelona (1998-2007)». Scripta Nova: Revista Electrónica de Geografía y Ciencias Sociales [en línea], XII, 270-132. <http://www.ub.es/geocrit/sn/sn-270-161.htm>.

BAyONA, J. y LÓPEZ-GAY, A. (2011). «Concentración, segregación y movilidad residencial de los extranjeros en Barcelona». Documents d’Anàlisi Geogràfica [en línea], 57 (3), 381-412. $<$ http://dx.doi.org/10.5565/rev/dag.234>.

Burriel, E. (2008). «La década prodigiosa del urbanismo español (1997-2006)». Scripta Nova [en línea], XII (270), 64. <http://www.ub.es/geocrit/sn/sn-270/sn-270-64.htm>.

- (2014). «El estallido de la burbuja inmobiliaria y sus efectos en el territorio». En: Albertos, J.M. y SÁnChez, J.L. (coords.). Geografía de la crisis económica en España. Valencia: Publicacions de la Universitat de València, 101-140.

- (2015). «Empty urbanism: The bursting of the Spanish housing bubble». Urban Research \& Practice [en línea]. <http://dx.doi.org/10.1080/17535069.2015.1110196>.

Catalán, B; Saurí, D.; Serra, P. (2008). «Urban sprawl in the Mediterranean? Patterns of growth and change in the Barcelona Metropolitan Region 1993-2000». Landscape and Urban Planning, 85, 174-184.

CECS (2005). «La nueva movilidad residencial». En: CECS. Informe España 2005. Madrid: Fundación Encuentro, 265-324.

Champion, A. (2001). «Urbanization, Suburbanization, Counterurbanization and Reurbanization». En: PADDISON, R. (ed.). Handbook of Urban Studies. Londres: SAGE, 143-161.

Clark, W.; Duque, R. y Palomares-Linares, I. (2015). «Place attachment and the decision to stay in the neighbourhood». Population, Space and Place [en línea]. <http://dx.doi.org/10.1002/psp.2001>.

Díaz-Pacheco, J. y García-Palomares, J.C. (2014). «Urban Sprawl in the Mediterranean Urban Regions in Europe and the Crisis Effect on the Urban Land Development: Madrid as Study Case». Urban Studies Research [en línea]. <http://dx.doi.org/10.1155/2014/807381>.

Domínguez, M. (2014). «Dinàmiques de metropolitanització: Ús i integració del territori». En: TRULléN, J. (dir.). Crisi econòmica, creixement de les desigualtats $i$ transformacions. Barcelona: IERM, 248-290.

EEA (2006). Urban sprawl in Europe: The ignored challenge. Copenhagen: European Environment Agency.

EtXezarreta, A.; Hoekstra, J.; Dol, K. y CAnO, G. (2012). «De la burbuja inmobiliaria a las ejecuciones hipotecarias». Ciudad y Territorio: Estudios Territoriales, XIV (174), 597-613.

Ewing, R.; Pendall, R. y Chen, D. (2002). Measuring sprawl and its impact: The character and consequences of metropolitan expansion. Washington, DC: Smart Growth America.

FERIA, J.M. y AlBerTos, J.M. (coords.) (2010). La ciudad metropolitana en España: Procesos urbanos en los inicios del siglo XXI. Pamplona: Thomson Reuters.

FONT, A. (2004). «La regió urbana de Barcelona: De la ciutat compacta als territoris metropolitans». En: FonT, A. L'explosió de la ciutat. Barcelona: COAC, 244-263.

GARCÍA COLL, A. (2009). "Migraciones interiores y transformaciones territoriales». En: Pons, J.; Montoro, C.; López, D. y Barcenilla, M.C. (eds.). Territorio y movilidad interior de la población en España. Pamplona: EUNSA, 13-40. 
- (2014). «The process of residential sprawl in Spain: Is it really a problem?». En: Benach, N. y Walliser, A. (eds.). Urban Challenges in Spain and Portugal. Londres: Routledge.

García Coll, A.; López Villanueva, C. y Pujadas, I. (2016). «Movilidad residencial en tiempos de crisis: El caso de la Región Metropolitana de Barcelona». Scripta Nova [en línea], XX, 549-4. <http://revistes.ub.edu/index.php/ScriptaNova/article/ view/17205/20743>.

García Montalvo, J. (2010). «Crisis económica y dinámica del ajuste inmobiliario en España». En: Federación de CAJAS DE AhOrRo. Crisis global: Hacia un nuevo modelo económico y social, 171-182.

García-Palomares, J.C. y GutiérreZ-Puebla, J. (2007). «La ciudad dispersa: Cambios recientes en los espacios residenciales de la Comunidad de Madrid». Anales de Geografía, 27 (1), 45-67.

Generalitat de Catalunya (2011). MUC. Mapa Urbanistic de Catalunya: Codificació i glossari de termes. Barcelona: Direcció General d'Ordenació del Territori i Urbanisme.

- (2015). MUC. Mapa Urbanistic de Catalunya: Dades bàsiques municipals i comarcals. Barcelona: Direcció General d'Ordenació del Territori i Urbanisme. Volúmenes correspondientes a Baix Llobregat, Alt Penedès, Barcelonès y Maresme.

Gielen, E. (2016). Costes del «Urban Sprawl» para la Administración local: El caso valenciano. Valencia: Servicio de Publicaciones de la Universitat de Valencia.

HenRY, G. (2007). «Análisis de costes de la baja densidad: Una lectura desde la sostenibilidad». En: Indovina, F. (coord.). La ciudad de baja densidad: Lógicas, gestión y contención. Barcelona: Diputación de Barcelona, 203-242.

Herce, M. y Magrinyá, F. (2007). "Los costes ambientales de la ciudad de baja densidad». En: IndovinA, F. (coord.). La ciudad de baja densidad: Lógicas, gestión y contención. Barcelona: Diputació de Barcelona, 243-264.

HorTAS-Rico, M. (2014). «Urban Sprawl and municipal budgets in Spain: A dynamic panel data analysis». Papers in Regional Science [en línea], 93 (3). <https://doi.org/10.1111/pirs.12022>.

Hortas-Rico, M. y Solé-Ollé, A. (2010). «Does Urban Sprawl Increase the Costs of Providing Local Public Services?: Evidence from Spanish Municipalities». Urban Studies [en línea], 47 (7), 1513-1540. <http://dx.doi.org/10.1177/0042098009353620>.

LÓPEZ DE LUCIO, R. (1998). «La incipiente configuración de una región urbana dispersa: El caso de la Comunidad Autónoma de Madrid (1960-1993)». En: MonCLús, F. (ed.). La ciudad dispersa. Barcelona: Centre de Cultura Contemporània, 5-16.

- (2004). «Morfología y características de las nuevas periferias: Nueve paisajes residenciales en la región urbana de Madrid». Urban, 9, 56-80.

López-GAY, A. (2011). « ¿Vuelve el centro?: Caracterización demográfica de los procesos de reurbanización en las metrópolis españolas». En: PUJADAS, I. et al. (eds). Población y espacios urbanos: Actas del XII Congreso de la Población española. Barcelona: AGE-Universitat de Barcelona, 163-180.

López Villanueva, C.; García-Coll, A.; Bretones, M.T. y Crespi, M. (2016). «El proceso de dispersión urbana en la Región Metropolitana de Barcelona: Los efectos de la crisis económica». Clivatge, 5, 290-331.

Marí-Klose, P. y Martínez Pérez, Á. (2015). «Empobrecimiento en tiempos de crisis: Vulnerabilidad y (des)protección social en un contexto de adversidad». Panorama Social, 22, 11-26. 
Miralles, C. y Tulla, A. (2012). «La Región Metropolitana de Barcelona: Dinámicas territoriales recientes». Boletín de la Asociación de Geógrafos Españoles, 58, 298-318.

MÓDENES, J.A. (2012). «Desequilibrios en las estructuras demográficas locales a raíz del último boom residencial: Problemas para la futura gestión sociodemográfica». En: ReQues, P. y Cos, O. de (eds.). La población en clave territorial: Procesos, estructuras y perspectivas de análisis. Santander: Ministerio de Economía y Competitividad, Gobierno de Cantabria, Asociación de Geógrafos Españoles y Universidad de Cantabria, 117-126.

Moliní, F. y Salgado, M. (2012). "Sprawl in Spain and Madrid: A low starting point growing fast». European Planning Studies [en línea], 20 (6), 1075-1092. <http://dx.doi.org/10.1080/09654313.2012.673570>.

MuNiz, I. y GARCía-López, M.A. (2013). "Anatomía de la dispersión urbana en Barcelona». Eure, 39 (116), 189-219.

Muñoz, F. (2010). Urbanalización: Paisajes comunes, lugares globales. Barcelona: Gustavo Gili.

- (coord.) (2011). Estratègies vers la ciutat de baixa densitat: De la contenció a la gestió. Barcelona: Diputació de Barcelona.

Mur, S. y ClusA, J. (2011). «El balanç fiscal municipal insostenible de la ciutat de baixa densitat». En: MuÑOZ, F. (coord.). Estratègies vers la ciutat de baixa densitat: De la contenció a la gestió. Barcelona: Diputació de Barcelona, 333-356.

NEL·LO, O. (2011). «Estrategias para la contención y gestión de las urbanizaciones de baja densidad en Cataluña. Ciudad y Territorio: Estudios Territoriales, XLIII (167), 81-98.

PujADAS, I. (2009). «Movilidad residencial y expansión urbana en la Región Metropolitana de Barcelona». Scripta Nova [en línea], 290. <http://www.ub.edu/geocrit/ sn/sn-290.htm>.

Pujadas, I.; Bayona, J.; Gil, F. y López Villanueva, C. (2013). «Pautas territoriales de la fecundidad en la Región Metropolitana de Barcelona (1986-2010)». Estudios Geográficos [en línea], 275, 585-609. <http://dx.doi.org/10.3989/estgeogr.201321>.

PujADAS, I.; BAyONA, J. y Rubiales, M. (2016). «Pautas territoriales y características sociodemográficas de las migraciones internas metropolitanas en las edades avanzadas». Finisterra: Revista Portuguesa de Geografía [en línea], LI (102), 121-142. $<$ http://dx.doi.org/10.18055/Finis4250>.

Pumares, P.; GARCíA-Coll, A. y ASENSIO, A. (2006). La movilidad laboral y geográfica de la población extranjera en España. Madrid: OPI.

Recaño, J. (2015). «Migraciones». En: Torres Albero, C. España: Situación Social. Madrid: CIS, 74-84.

Richardson, H.W. y BAE, C.H.H. (2004). Urban Sprawl in Western Europe and the United States. Londres: Ashgate.

Rubiera, F.; González Marroquín, V.M. y Pérez Rivero, J. (2016). «Urban Sprawl in Spain: Differences among cities and causes». European Planning Studies [en línea], 24 (1). <http://dx.doi.org/10.1080/09654313.2015.1080230>.

Smith, D.P.; Finney, N.; Halfacree, K. y Walford, H. (2015). «Understanding of Internal Migration Process Using Integrated Geographical Perspectives». En: SMITH, D.P. et al. (eds.). Intenal Migration: Geographical Perspectives and Processes. Londres: Ashgate, 165-178. 
Susino, J. y DuQue, R. (2013). «Veinte años de suburbanización en España (19812001): El perfil de sus protagonistas». Documents d'Anàlisi Geogràfica, 59 (2), 265-290.

VALDUNCIEL, J. (2013). «Tipología de las formas de crecimiento del urbanismo expansivo». En AA.VV. Espacios insulares y de frontera, una visión geográfica. Actas XXIII Congreso de Geógrafos Españoles. AGE-Universtitat de les Illes Balears, 709-717.

VilÀ, G. y GaVAlDA, J. (2013). «Efectos del urbanismo disperso y consecuencias para la sostenibilidad social: Análisis de la Región Metropolitana de Barcelona». Cadernos Metropole, 29 (15), 15-39. 